\title{
Circulating Tumor Microemboli: Progress in Molecular Understanding and Enrichment Technologies
}

Muhammad Umer ${ }^{1}$, Ramanathan Vaidyanathan ${ }^{2}$, Nam-Trung Nguyen ${ }^{1}$, Muhammad JA Shiddiky*1,3

\section{Affiliations}

1 Queensland Micro- and Nanotechnology Centre (QMNC), Griffith University, Nathan Campus, QLD 4111, Australia.

2 Department of Biomedical Engineering, National University of Singapore (NUS), Singapore 117581.

3 School of Environment and Science, Griffith University, Nathan Campus, QLD 4111, Australia.

* Corresponding Author

Email: m.shiddiky@griffith.edu.au

Conflict-of-interest: Authors declare no conflict of interest

Keywords: Circulating tumor cells (CTCs), Circulating tumor microemboli (CTM), CTC clusters, metastasis, epithelial to mesenchymal transition (EMT)

List of Abbreviations: CTC, circulating tumor cells; CTM, circulating tumor microemboli; VEGF-A, vascular endothelial growth factor A; DCIS, ductal carcinoma in situ; DTC, disseminated tumor cells; EMT, epithelial-mesenchymal transition; ECM, extracellular matrix; SCLC, small cell lung cancer; K14, keratin 14; TGF- $\beta$, transforming growth factor $\beta$; MET, mesenchymal-epithelial transition; FGF, fibroblast growth factor; HER2, human epithelial growth factor receptor 2; EGFR, epidermal growth factor receptor; PSA, prostate specific antigen; CK, cytokeratin; WBC, white blood cells; ISET, isolation by size of epithelial cells; CAM, collagen adhesion matrix; FMS, flexible micro spring array; iFISH, immunoFluorescence in situ Hybridization; eDAR, ensemble-decision aliquot ranking; APD, avalanche photodiodes; HB-Chip, herringbone chip; DLD, deterministic lateral displacement; PDMS, poly(dimethylsiloxane); SLB, supported lipid bilayer; CMx, cells captured in maximum; PMMA, poly(methyl methacrylate; CRC, colorectal cancer; MCA, microcavity array; DFF, dean flow fractionation; RBC, red blood cells. 


\begin{abstract}
Circulating tumor cells (CTCs) and their clusters, also known as circulating tumor microemboli (CTM), have emerged as valuable tool that can provide mechanistic insights into the tumor heterogeneity, clonal evolution, and stochastic events within the metastatic cascade. However, recent investigations have hinted that CTM may not be mere aggregates of tumor cells but cells comprising CTM exhibit distinct phenotypic and molecular characteristics in comparison to single CTCs. Moreover, in many cases CTM demonstrated higher metastatic potential and resistance to apoptosis as compared to their single cell counterparts. Thus, their evaluation and enumeration may provide a new dimension to our understanding of cancer biology and metastatic cancer spread as well as offer novel theranostic biomarkers. Most of the existing technologies for isolation of hematogenous tumor cells largely favor single CTCs, hence there is a need to devise new approaches, or re-configure the existing ones, for specific and efficient CTM isolation. Here we review existing knowledge and insights on CTM biology. Furthermore, a critical commentary on current and emerging trends in CTM enrichment and characterization along with recently developed ex-vivo CTC expansion methodologies is presented with the aim to facilitate researchers to identify further avenues of research and development.
\end{abstract}

\title{
1. Introduction
}

Millions of cells, both individually or as clusters, exuviate from primary and metastatic tumor masses and find their way into the bloodstream throughout the course of carcinogenesis (Lambert et al., 2017; Massague and Obenauf, 2016). These circulating tumor cells (CTCs) can potentially portray intratumor genetic heterogeneity as well as temporal and therapy induced molecular evolution more comprehensively as compared to single-site biopsies (Pantel and Speicher, 2016). Furthermore, as a fraction of CTCs most likely represents metastasiscompetent cell population, CTC research has gained widespread interest in recent years (Aceto et al., 2014). An intriguing feature of this circulation bound tumor cell population is the observation that about $5 \%$ of it is comprised of heterogeneous multicellular clumps of 3-100 cells (Aceto et al., 2014; Yu et al., 2013). These aggregates have been termed as circulating tumor microemboli (CTM), CTC Clusters, or circulating micrometastases (Aceto et al., 2014).

As CTCs have come to be invariably associated with metastasis, it is no surprise that the earliest mentions of hematogenous tumor cells are found in discussions surrounding the development 
of cellular theory of tumor invasion and metastasis (Figure 1). Initial descriptions of tumor cells translocating from primary mass and invading locally and into the veins by were reported by Récamier (Récamier, 1829) and later on by Thiersch (Thiersch, 1865). Langenbeck’s pioneering microscopic observations provided the first experimental evidence of tumor cells in blood circulation (Langenbeck, 1841). A few years later Australian pathologist Thomas Ashworth reported similar observations (Ashworth, 1869). Further, prominent $19^{\text {th }}$ century pathologist Rudolf Virchow suggested that metastasis results from arrest of "tumor cell emboli" in vasculature (Talmadge and Fidler, 2010; Virchow, 1858). It is interesting to note here that many of the early researchers preferred to use the term "tumor emboli" rather than "tumor cells" while describing the migrant tumor cell population presumably involved in metastatic spread (Coman et al., 1951; Zeidman, 1957). Several investigators during latter half of the $20^{\text {th }}$ century, in their experimental induction of metastasis studies, highlighted the fact that aggregates or clusters of tumor cells hold higher metastatic potential as compared to single cells (Coman et al., 1951; Fidler, 1973; Liotta et al., 1976; Thompson, 1974; Watanabe, 1954; Zeidman, 1957). Among these, numerous animal studies established a direct correlation between size, number, and concentration of CTC clusters with their metastatic potential (Fidler, 1973; Knisely and Mahaley, 1958). Moreover, these "tumor emboli” were shown to be capable of traversing pulmonary circulation in small animals, further highlighting the predominant role they might play in metastasis (Zeidman and Buss, 1952).

However, despite these early observations, research in this space during the subsequent decades largely overlooked CTM. This oversight may possibly be attributed to the inability of earlier CTC enrichment approaches in differentiating between single cells and microemboli, or in some cases actually causing their disruption (Yu et al., 2011). Furthermore, the conceptual framework of metastasis development based on Nowell's clonal evolutionary model (Nowell, 1976) also posited single metastatically competent cells as central players in this extremely complex phenomenon; metastasis arises from clonal expansion of single disseminated tumor cells (Chaffer and Weinberg, 2011; Yu et al., 2011). Therefore several decades later CTM could be identified in human peripheral blood (Brandt et al., 1996; Molnar et al., 2001) and it is only very recently that a full appraisal of their significance in metastasis has started to emerge (Aceto et al., 2014; Au et al., 2016; Hou et al., 2011) (Figure 1).

Over the years, research on single CTCs has made tremendous contributions to our understanding of invasion-metastasis cascade as well as intratumor heterogeneity and temporotherapeutic evolutionary dynamics (Lambert et al., 2017; Massague and Obenauf, 2016; Pantel 
and Speicher, 2016; Thiele et al., 2017). Additionally, their potential as minimally invasive biomarkers for prognosis, recurrence monitoring, and precision theranostics has also been demonstrated (Alix-Panabieres et al., 2012; Joosse et al., 2015; Thiele et al., 2017). The immense interest that CTC research has garnered can easily be gauged by the number of publications (>3000 since January 2015, PubMed) and currently registered clinical trials using CTCs as biomarkers (> 440, ClinicalTrials.gov). Nonetheless, recent discoveries in CTM biology have opened up new perspectives in pathophysiology of cancer, specifically metastasis, as well as its clinical management. Evidence has started to accumulate suggesting that the contribution of CTM to metastatic cancer spread may be far greater than previously appreciated (Aceto et al., 2014; Au et al., 2016; Cheung et al., 2016). CTM have been detected in several cancers such as; prostate (Aceto et al., 2014; Brandt et al., 1996), pancreatic (Xu et al., 2017), breast (Ozkumur et al., 2013), colorectal (Chen et al., 2016), as well as small and non-small cell lung cancers (Hou et al., 2011; Hou et al., 2012). Moreover, studies have demonstrated that presence of even a single CTM in patient blood is significantly correlated with reduced progression free survival rates (Au et al., 2017; Hou et al., 2012; Jansson et al., 2016; Mu et al., 2015). Thus, CTM may prove to be a valuable resource for the development of improved diagnostic and prognostic biomarkers and may also help to gain further insights into the molecular signatures and phenotypes associated with the stochastic events in metastatic cascade. This review aims to summarize the recent advances in our understanding of CTM biology. Moreover, we have presented an overview of technologies and devices, with more emphasis on methods employing microfluidic principles that have been used to enrich CTM and also identify specific functional and phenotypic characteristics of CTM including ex vivo CTC expansion under culture environments.

\section{Biology of Circulating Tumor Microemboli}

Research into the unique phenotypic and molecular characteristics of patient derived CTM, that supposedly favor their increased metastatic potential and hematogenous survival as well as collective migration, has so far been hampered by the limited capacity of methods and devices currently in use to reliably isolate and recover intact CTM. Although, various preclinical and clinical studies have provided important insights, our current understanding of various aspects of CTM biology, such as mechanisms underpinning collective migration, is still limited. Nevertheless, this is a burgeoning area of research and with the development of novel CTM isolation devices, or adaptation of earlier methods to this end, new insights are 
expected to emerge in the years to come. A brief overview of general properties of hematogenous tumor cells, with more emphasis on the unique phenotypic and functional characteristics of CTM and the various cells that make up these clusters is presented hereunder. Key features of CTM biology are outlined in Figure 2. Readers may also refer to some of the excellent recent reviews on this vast body of knowledge (Alix-Panabieres and Pantel, 2014; Hong et al., 2016; Krebs et al., 2014; Pantel and Speicher, 2016; Thiele et al., 2017).

\subsection{Morphology, Cellular Composition, and Rarity of CTM}

The number of cells within a CTM generally ranges from 2 to 50. In some cases, CTM made up of more than 100 cells have also been observed (Aceto et al., 2014; Hou et al., 2012). The overall diameter of a CTM may range from 20 to $130 \mu \mathrm{m}$ (Krebs et al., 2012). In addition to the tumor cells, other non-tumor cell types associated with CTM include platelets (Labelle et al., 2011; Laubli et al., 2006), fibroblasts (Duda et al., 2010), endothelial cells (Duda et al., 2010; Kusters et al., 2007), leukocytes (Wels et al., 2008), and pericytes (Kusters et al., 2007). CTCs are extremely rare; 1 out of a billion blood cells, or 1 against 10 million PBMCs, per milliliter of blood, and their number may be even lower in non-metastatic cancer patients. CTM on the other hand comprise only 2-5\% of the total CTC population (Aceto et al., 2014; Krebs et al., 2014). Morphologically, CTM population shows a high level of heterogeneity. CTM of various morphological appearances like irregular clusters, elongated strands, rings, or even triangular geometry have been observed (Hou et al., 2011; King et al., 2015). Furthermore, it has been observed that individual tumor cells within a CTM are smaller than single CTCs, sometimes having sizes equal to those of surrounding leukocytes (Cho et al., 2012; Hou et al., 2013).

\subsection{Circulation Bound Tumor Microemboli are Short Lived}

In addition to being very rare, hematogenous tumor cells are short lived. In breast cancer patients, circulation time of single CTCs has been found to be merely 1-2.4 hours (Meng et al., 2004), while in non-metastatic prostate cancer patients, CTCs are not detectable 24 hours post resection (Stott et al., 2010b). The half-life of CTM on the other hand is at least three times less than single CTCs; 6-10 min vs 25-30 min (Aceto et al., 2014). Shorter half-life of CTM has been attributed to their rapid entrapment in small capillaries. However, 10 min half-life is still considerably higher than the time required for a single pass through the whole circulatory system (Aceto et al., 2015). Recently, it has been reported that CTM of up to 20 cells are able to reversibly reorganize themselves as a single-file and successfully traverse microfluidic 
channels of diameters $(5-10 \mu \mathrm{m})$ comparable to those of small human capillaries thus explaining their survival beyond the time required for single pass through circulatory system (Au et al., 2016). Nonetheless, due to their large sizes and slower traveling speed, CTM are more likely to get trapped in microvasculature (Choi et al., 2015; Peeters et al., 2015; Phillips et al., 2015) suggesting the possible reasons for their rapid clearance from circulation, and also further implicating that large number of CTM are initially released from primary mass but are quickly trapped and our current understanding about their frequency may be an underestimation (Aceto et al., 2015).

\subsection{Origin of CTM}

Blood borne cancer cells may form intravascular aggregates after they get attached to the endothelium of microvasculature (Al-Mehdi et al., 2000; Glinsky et al., 2003). Consequently, it was suspected earlier that CTM may originate from intravascular aggregation of single CTCs. However, Aceto et al. in their study suggested that CTM in fact break off from primary tumor mass as clusters (Aceto et al., 2014). Similar observations have been made in pancreatic cancer mouse model (Maddipati and Stanger, 2015). Besides, it has also been proven that intravascular aggregation of CTCs might be impossible due to shear forces in circulation (Hong et al., 2016). Ex vivo formation of CTM during sample processing has been ruled out by the observations that they are identified in only a subset of patients despite the samples being processed identically, and they have been found in lymphovascular spaces surrounding primary mass in resected tumor specimens (Hou et al., 2012; Sugino et al., 2004; Tomlinson et al., 2001). Furthermore, cells within CTM stain negative for proliferation marker Ki67 indicating that CTM have not originated from active proliferation of single CTCs and have in fact broken off from primary tumor as clusters (Hou et al., 2012).

As will be discussed in more detail later (Section 2.5), plakoglobin is a key cell-cell adhesion protein whose expression is upregulated in breast cancer related CTM and that appears to be vital for CTM integrity. Intriguingly, it was observed that primary breast tumors exhibit a "patchy" pattern of plakoglobin expression; regions or patches of high plakoglobin expression interspersed between no-plakoglobin region, giving rise to the possibility that CTM originate from these high plakoglobin expressing regions (Aceto et al., 2014) (Figure 2A). A slightly different model of CTM origin has also previously been demonstrated in a subcutaneous melanoma mouse model (Kats-Ugurlu et al., 2009; Kusters et al., 2007). Constitutive vascular endothelial growth factor A (VEGF-A) expression in primary tumors induces formation of 
multicellular micronodules that bulge out from primary mass. VEGF-A production by tumor cells also causes dilation of surrounding vasculature thus facilitating the intravasation of these bulging micronodules.

Genetic heterogeneity within metastatic lesions is one of the long-standing issues in metastasis biology which also calls into question the single-cell clonal expansion model of metastasis development (Cheung et al., 2016; Maddipati and Stanger, 2015). Although multiple seeding events of individual CTCs over time cannot be ruled out as a source of genetically diverse tumor clones within a single metastatic lesion, recent evidence rather suggests that origin of heterogeneity may lie in the clonal composition of CTM. Aceto et al.'s study made a striking observation that composition of CTM is oligoclonal (oligo- a few, descending from a few distinct neighboring clones) and they are possibly a cluster of neighboring cells within a primary tumor mass (Aceto et al., 2014). This finding has further been substantiated by a recent mouse-model study of breast cancer metastasis (Cheung et al., 2016). Cheung et al.'s study proved that composition of collectively migrating tumor cell clusters across all the major stages of metastatic cascade; detachment, invasion through surrounding stroma, circulation bound CTC clusters, and distant micro- and macro-metastases, was indeed polyclonal and that $>90$ $\%$ of metastases arise from these collectively migrating polyclonal cell clusters (Cheung et al., 2016).

\subsection{Timing of Tumor Cell Dissemination}

Experimental and clinical evidence supports the assumption that dissemination of cells is an early event in carcinogenesis (Pantel and Speicher, 2016). For example, in a pancreatic cancer mouse model, hematogenous tumor cells with mesenchymal and stem cell like phenotype can be detected even before any overt primary tumors could be diagnosed (Rhim et al., 2012). However, metastatic ability of these "early exiting" cells has been questioned. In ductal carcinoma in situ (DCIS) breast cancer patients, although disseminated tumor cells (DTCs) in bone marrow could be detected in a sizeable proportion of patients, not all of them suffered relapse indicating that early exiting cells may not necessarily be metastasis competent (Sanger et al., 2011). On the other hand, two recent studies have shown in mouse models of breast cancer, that not only a subpopulation of early exiting cancer cells with specific molecular signature are invasive and can spread to distant organs, but also that these cells from early, low density lesions possess more stemness and metastatic potential compared to those exiting from late, dense, and advanced tumors (Harper et al., 2016; Hosseini et al., 2016). These studies 
have offered substantial evidence in favor of the "independent evolution" or "parallel progression" model of metastasis (Klein, 2009). It can thus be conferred that although CTCs/CTM detach from primary tumors quite early, they might not be able to initiate metastasis before undergoing further evolution at a metastatic site.

\subsection{Epithelial to Mesenchymal Transition and Active vs Passive Entry into Circulation}

One of the long-standing questions in CTC biology is whether the cells are released actively, or this detachment event is a passive outcome of the combined effect of various factors such as tumor growth, compromised tumor vasculature, and friction forces. VEGF secreted by cancer cells stimulates the formation of de novo blood vessels around tumor mass, a process known as angiogenesis. However, rapid angiogenesis around tumor cells may lead to the formation of blood vessels with loosely connected endothelial cells, thus resulting in "leaky vessels" (Figure 2A). Coupled with outward push that cells may experience during tumor growth, these leaky vessels may be responsible for passive entry of CTCs/CTM to the circulation (McDonald and Baluk, 2002; Thiele et al., 2017). On the other hand, for active release, cells might need to gain special characteristics which enable them not only to lose their cell-to-cell junctions but also invade through surrounding extracellular matrix, basement membranes and ultimately endothelial lining of blood vessels. Epithelial-to-mesenchymal transition (EMT) has been suggested as the underlying mechanism (Hanahan and Weinberg, 2011). However, the predominant use of epithelial markers during CTC enrichment has so far hindered the systematic characterization of CTCs with mesenchymal phenotype. Interestingly, although CTCs with mesenchymal characteristics have indeed been observed in a variety of cancers, considerable intra- and inter-patient heterogeneity in expression of mesenchymal markers has been observed (Hou et al., 2011; Yu et al., 2013). Notably, in breast cancer patients the ratio of mesenchymal to epithelial CTCs was found to have a direct correlation with response to therapy (Yu et al., 2013). It has long been disputed whether EMT hypothesis in actual fact is needed to explain the biological behaviors such as metastasis (Tarin et al., 2005). Recent data appears to support EMT skeptics; platelet derived factors induce EMT in tumor cells hence suggesting post-intravasation transformation (Labelle et al., 2011), and EMT is rather dispensable for metastasis in pancreatic cancer (Zheng et al., 2015). Taken together, evidence suggests that although occurrence of EMT in tumor cells is quite common and may have vital influence in various aspects of cancer biology, such as chemoresistance (Zheng et al., 2015), its precise role in metastasis as well as active intravasation of CTCs is still not clear. 
While on one hand EMT has been found to be dispensable for metastasis, EMT hypothesis rather contradicts the CTM evidence. For cells to break away from primary mass as clusters, maintaining strong intra-cluster cell-to-cell adhesion is a prerequisite. Friedl and Wolf argued that certain cells may acquire the ability to degrade extracellular matrix (ECM) around them thus creating a path through ECM for other cells to follow (Friedl and Wolf, 2009). "Cell cooperation" theory has also been demonstrated in a hamster cheek pouch carcinoma model (Tsuji et al., 2008). Subcutaneous inoculation of either cell types (epithelial or mesenchymal) produced primary tumors, however only tumor masses derived from cells of mesenchymal phenotype showed any signs of invasion into the adjacent tissues or blood vessels. Moreover, lung metastasis could only be established when both cell types were inoculated together (Tsuji et al., 2008). Another mouse model of small-cell lung cancer (SCLC) also lends credence to the so-called cell cooperation theory (Calbo et al., 2011). More exquisite details of molecular programs associated with collectively migrating tumor cell clusters have recently been reported. It was shown that among collectively migrating tumor cells, a certain Keratin 14 expressing (K14+) subpopulation may act as "leader" cells (Cheung et al., 2013). Cheung et al. utilized ex vivo 3D breast tumor organoids to demonstrate that $\mathrm{K}_{14}{ }^{+}$cells are concentrated at tumor-stromal borders and lead multicellular "invasive strands" in to the adjacent muscles. $\mathrm{K}_{1} 4^{+}$cells not only displayed a distinct basal epithelial program but also a particular "protrusive" morphology. $\mathrm{K}_{1} 4^{+}$cells that switch to this protrusive morphology lead the collectively invading strands of cancer cells (Figure 2A) (Cheung et al., 2013). Possible involvement Furthermore, CTM at various stages of metastasis cascade are enriched for $\mathrm{K} 14^{+}$ cells, on the contrary proliferating metastatic masses show enrichment of K14- cells (Cheung et al., 2016). Of relevance here, is the observation that cells within CTM predominantly express mesenchymal markers (Yu et al., 2013), raising the question as to how tumor cells may migrate collectively after they have lost cell-cell adhesion capabilities. However, it has also been observed that cells within a CTM undergo partial EMT, i.e. gaining migratory characteristics of mesenchymal cells while retaining cell-to-cell adhesion of epithelial cells (Zheng et al., 2017). Relevant studies have also suggested that EMT is a rather "fluid" phenomenon and circulating cells with varying degrees of EMT may be observed (Kalluri, 2009). Single cell RNA sequencing of CTCs and cells within CTM, revealed enrichment of specific transcripts among CTM cells. Notable among these is plakoglobin, a crucial cell-cell adhesion molecule, whose expression was found to be increased by as much as 200-fold in CTM as compared to single CTCs (Aceto et al., 2014). Plakoglobin might have a key role in maintaining CTM integrity as its knockdown results in the disintegration of CTM (Aceto et al., 2014). In addition 
to plakoglobin, $\mathrm{K}_{14}{ }^{+}$subpopulation among CTM is specifically enriched for desmosome and hemidesmosome complex related genes (Cheung et al., 2016), an observation that further elaborates on mechanisms involved in maintaining the integrity of CTM.

\subsection{Metastatic Potential of Circulating Tumor Microemboli}

Recent research has highlighted three distinct features of CTM biology; i) up to 100-fold increased metastatic potential as compared to single CTCs (Aceto et al., 2014; Au et al., 2016), ii) overall increased survival, and iii) resistance to therapy (Bithi and Vanapalli, 2017). Analysis of several cancer patients revealed that although a significant proportion of circulating single cancer cells are apoptotic, apoptosis among cells that comprise CTM was absent (Hou et al., 2012). Increased resistance to anoikis (apoptosis induced by inadequate cell/ECM interaction (Frisch and Screaton, 2001)) by virtue of retaining crucial cell-to-cell junctions has been implicated as the fundamental mechanism (Dasgupta et al., 2017). However, cancer cells in general may have inherent resistance to anoikis due to several altered pathways (Paoli et al., 2013), such as increased expression of neurotrophic receptor TrkB (Douma et al., 2004), thus suggesting additional mechanisms may also be involved. It has been proposed that "intracluster" crosstalk between different cells is also helpful in reducing apoptosis (Aceto et al., 2014). In this regard, several studies have underscored the role that platelets play in supporting enhanced survival of tumor cells. For example, platelets physically shield associated tumor cells from shear forces in circulation (McCarty et al., 2000), induce EMT in cancer cells, and platelet derived TGF- $\beta$ may help tumor cells to evade immune attack (Kopp et al., 2009). Furthermore, it has been demonstrated that association with stromal components, particularly fibroblasts, not only enhances the survival of tumor cells within a CTM, but also provides growth advantage to them after seeding at distant sites (Duda et al., 2010). A recent gene expression analysis has shown elevated levels of IL6, that activates various antiapoptotic genes, as well as BCL2, an antiapoptotic gene itself, in CTM specifically compared to single CTCs. Additionally, CTM also exhibited high expression of ERCC1 which plays role DNA repair. Collectively, this gene expression pattern indicates increased survival advantage. On the other hand, CTM also showed gene signature associated with higher migratory ability and enrichment of IL17 signaling pathway (suggestive of increased invasiveness), the markers which may partly explain higher metastatic potential of CTM (Murlidhar et al., 2017).

Association with other cell types like endothelial cells (Upreti et al., 2011) and WBCs (Fidler, 1974) may contribute to the enhanced metastatic potential of tumor cells in CTM. Although a detailed comparative molecular characterization of single CTCs and cells within CTM is still 
lacking, single cell RNA sequencing revealed very little difference in expression patterns among single CTCs and CTM obtained from same breast cancer patients (Aceto et al., 2014). This data suggests that CTM associated non-tumor cells could potentially play an important role in increased metastatic capability of CTM, a hypothesis which may have profound implications for the "seed and soil" theory; cancer cell (seeds) carrying their own soil (associated cells) thus making a niche that is not only supportive to their survival in circulation but also facilitates their adaptation and growth in distant tissues. It is currently not clear whether all the tumor cells within a CTM possess equal metastatic potential or certain cells are more metastatic than the others. Although studies suggest that cells within CTM may differ in their metastatic capabilities (Kusters et al., 2007), specific associated molecular characteristics are not known. Recently, an interesting observation has been reported that not all hematogenous CTC clusters are malignant, even though these non-malignant populations also originate from primary mass. This CTM subpopulation express both epithelial and mesenchymal markers, much like single CTCs, but phenotypically they are in fact aggregates of endothelial cells, lacked the genetic variability of primary tumor, and were not cancerous (Cima et al., 2016). Cells within CTM were known to be negative for proliferation marker Ki67 (Krebs et al., 2012). Lack of proliferation among CTM comprising cells may implicate that they are resistant to most of the currently available cancer therapies (Hou et al., 2012), emphasizing the need for development of CTM targeting therapies.

\subsection{CTM in Clinic: Diagnostic, Prognostic, and Predictive Potential}

With growing evidence on the diagnostic potential of CTM across multiple cancer types, clinical relevance of CTM with respect to frequency, size, cellular composition, gene expression signatures etc. remains to be understood. Over the years, several investigations have suggested a strong correlation of CTM baseline levels with reduced progression free survival (PFS) as well as overall survival rates (OS) across multiple cancer types including SCLC (Hou et al., 2012), (Hou et al., 2012) breast, gastric, liver, colorectal, as well as melanoma (See (Giuliano et al., 2018) and the references therein). Apart from being considered to be a standalone prognostic marker in pancreatic ductal adenocarcinoma (Chang et al., 2016), CTM detection has also been linked to poor prognosis in preoperative specimens (Murlidhar et al., 2017). Similarly, CTM positive advanced colorectal cancer patients survived shorter compared to CTM negative patients (Zhang et al., 2017). Studies have also indicated that identification of CTM in the patient's blood post commencement of therapy is suggestive of reduced PFS and OS. In a randomized phase II clinical trial in triple negative breast cancer (TNBC) patients 
receiving nanoparticle albumin-bound paclitaxel + tigatuzumab, detection of CTM at days 15 and 29 post commencement of therapy was correlated with significantly reduced PFS (Paoletti et al., 2015). While CTM detection at baseline generally indicated a lower PFS, persistence or appearance of CTM after therapy indicated reduced PFS highlighting the prognostic potential of CTM (Fanelli et al., 2017). Furthermore, it has been shown that in NSCLC patients CTM prevalence is correlated with stage of the disease (Krebs et al., 2012) whilst presence of CTM was correlated with resistance to therapy in epithelial ovarian cancer (EOC) patients (Lee et al., 2017). Taken together, these investigations suggest the potential for CTM as diagnostic, prognostic, and predictive biomarker. However, considering the sample size and variation across multiple isolation approaches utilized, further studies will be needed to establish the clinical potential of CTM with respect to correlation of morphology and molecular make up of CTM during therapy or cancer management.

\section{Challenges in the Development of CTM Enrichment Methods}

Rapid developments in single cell technologies over the past few years have revolutionized our understanding and approach towards many diverse aspects of biology such as genetics, microbiology, neurobiology, epigenetics, and cancer research (Liang and Fu, 2017). While methods for isolation of random single cells from a bulk tissue are now well developed, capture of rare cells like CTCs is still a formidable challenge (Wang and Navin, 2015). Rare cells are defined as a subpopulation which represents less than $0.01 \%$ of heterogenous cell population (Proserpio and Lonnberg, 2016). Although isolation and detection of CTCs is a big challenge, owing to their rarity and ephemeral appearance in circulation, CTM pose another layer of predicament not only because they are even rarer and short lived as compared to single CTCs, but also because in many of the cases sample processing may dissociate CTC clusters. Following subsections present a discussion on metrices that can be used to evaluate the performance of CTM enrichment devices as well as the relative significance of each of these metrices for specific applications of these platforms. Moreover, we also discuss biological and technical challenges that must be taken into consideration while devising new methods or adapting current state-of-art single CTC technologies for CTM isolation.

\subsection{Performance Evaluation of Enrichment Platforms}

Performance potential of a CTC/CTM enrichment platform can be evaluated based on various parameters. The most important parameters are: (i) capture efficiency/sensitivity, (ii) purity/specificity, (iii) enrichment rate, (iv) throughput, (v) ease of retrieval, and (v) viability. 
Capture efficiency or recovery rate of a CTC isolation device is defined as the ratio of cells or their clusters detected relative to the total number of CTCs or the clusters present in the sample (eq 1). In clinical settings where CTC/CTM enumeration and establishing its correlation with disease characteristics and progression as well as therapeutic efficacy is the primary aim, capture efficiency of a device is a crucial parameter. Recovery rate is a particularly important metric to evaluate diagnostic potential of the device for early stage cancers when concentration of CTCs/CTM in blood is relatively low. On the other hand, purity is the ratio of CTCs to total cells in enriched sample. In other words, the level of contamination with background cells, such as RBCs and WBCs, is defined as purity of capture (eq 2a). In terms of CTM, purity can be defined as the ratio of CTM captured by the device to the total number of single CTCs, background cells, and CTM present in the captured output (eq 2b). Purity may be a critical concern when downstream analysis of captured cells/clusters is required. Enrichment rate, the ratio of CTCs/CTM in blood before and after enrichment, indicates the selectivity of separation process (eq 3a and b) (Esmaeilsabzali et al., 2013; Jin et al., 2014).

$$
\begin{aligned}
& \text { Capture Efficienc } y_{C T M}=\frac{C T M_{\text {recovered }}}{C T M_{\text {sample }}} \\
& \text { Purity }_{C T C}=\frac{C T C_{\text {recovered }}}{{\text { CTC } C_{\text {recovered }}+\text { Background Cells }}_{\text {recovered }}} \\
& \text { Purity }_{C T M}=\frac{C T M_{\text {recovered }}}{C T M_{\text {recovered }}+C T C_{\text {recovered }}+\text { Background Cells } \text { recovered }} \\
& \text { Enrichment Rate } \text { RTC }_{C}=\frac{\left(C T C / \text { Background Cells }_{\text {recovered }}\right.}{(C T C / \text { Background Cells })_{\text {sample }}} \\
& \text { Enrichment Rate }_{C T M}=\frac{(C T M / \text { Background Cells }+ \text { CTC })_{\text {recovered }}}{(C T M / \text { Background Cells }+ \text { CTC })_{\text {sample }}}
\end{aligned}
$$

The speed at which a device can process samples, i.e. throughput, is also a noteworthy performance metric, specifically when clinical application of the device is desired where large sample volumes may need to be processed for meaningful conclusions. For continuous-flow systems such as microfluidic devices, the throughput is defined as the fluid volume flowing through the device per unit time (typically $\mathrm{mlh}^{-1}$, eq $4 \mathrm{a}$ ). Throughput can also be defined, especially for non-continuous-flow devices, as the number of cells processed per unit time (eq 4b) and is considered more useful as concentration of samples may vary. The percentage of 
viable cells/clusters that can be obtained from the total CTCs/CTM recovered (eq 5) and the ease with which these viable cells can be retrieved from the device for further investigations are also important criteria which may need to be weighed in circumstance when post-recovery characterization and analysis is intended (Esmaeilsabzali et al., 2013). Additionally, repeatability, cost effectiveness, and compatibility with automation may also be considered while designing a new device or determining the suitability of an existing platform.

$$
\begin{aligned}
& \text { Throughput }=\frac{\text { Volumetric Flow Rate }}{\text { Time }} \\
& \text { Throughput }=\frac{\text { Number of Cells Processed }}{\text { Time }} \\
& \text { Viability }{ }_{C T C(\text { or CTM })}=\frac{\text { Viable CTC }(\text { or CTM })_{\text {Recovered }}}{\text { Total CTC }(\text { or CTM })_{\text {Recovered }}}
\end{aligned}
$$

\subsection{Heterogeneity and Specificity of Biochemical and Physical Properties}

Heterogeneity and specificity of markers/properties that are used to distinguish and isolate CTCs/CTM against a background of billions of blood cells are the major biological challenges. Marker dependent enrichment technologies that rely on surface expression of specific proteins are the most widely used CTC enrichment methods. EpCAM is the most frequently used cell surface marker for positive enrichment of CTCs while different subtypes of cytokeratin (CK) are targeted for post-enrichment specific identification of CTCs/CTM. This EpCAM/CK combination has been employed in a range of techniques including the only FDA approved platform CellSearch ${ }^{\circledR}$ (Allard et al., 2004) as well as novel microfluidics based platforms (Nagrath et al., 2007; Ozkumur et al., 2013; Stott et al., 2010a). However, the specificity of EpCAM for targeting cancer cells has been challenged as circulating epithelial cells can be detected in other disease conditions such as benign colon disease (Pantel et al., 2012). Moreover, EMT in cancer cells may lead to the downregulation of both EpCAM and CK resulting in exclusion of CTCs with mesenchymal phenotype. Importantly, cells within CTM have been found to express high levels of mesenchymal markers and as CTM are known to exhibit hybrid epithelial-mesenchymal phenotype (Hou et al., 2011; Khoja et al., 2012), it may very well be possible that a substantial portion of CTM population had gone undetected in studies that relied on current marker dependent platforms. Two prominent mesenchymal markers have been suggested as alternatives to broaden the capture capacity of markerdependent approaches, namely; N-cadherin and the cytoskeletal protein vimentin (AlixPanabieres and Pantel, 2014). However, in addition to being expressed by normal blood cells, 
considerable heterogeneity, or even a complete absence, of vimentin expression among cells within CTM has also been reported (Bednarz et al., 2010; Harouaka et al., 2014; Hou et al., 2011), thus casting doubts on the applicability of vimentin as suitable CTM enrichment marker. Other non-epithelial markers under investigation for single CTC isolation include nuclear localization of $\beta$-catenin, or increased expression of various transcription factors like SNAI1, SNAI2, ZEB1, ZEB2, TWIST, TCF etc. (Alix-Panabieres and Pantel, 2014). However, expression patterns of these markers in CTM comprising cancer cells are currently not known. Actin dependent bundling protein Plastin-3 has also recently been suggested as reliable marker because it is neither downregulated during EMT nor is it expressed by blood cells (Yokobori et al., 2013). Nevertheless, as CTC population at any given time point is essentially a heterogenous mixture of cells showing variable expression of EMT associated markers, use of one marker alone may not be able to faithfully capture all the CTCs or CTM. Yu et al. were able to successfully characterize CTCs exhibiting broad range of epithelial-mesenchymal phenotypes by using a cocktail of antibodies targeting various epithelial and mesenchymal markers (Yu et al., 2013). Given the heterogeneity of cells within a CTM, the use of such an antibody cocktail for CTM enrichment is highly desirable. Nonetheless, using a broad spectrum cocktail may decrease specificity of the method and may lead to false positive results (AlixPanabieres and Pantel, 2014).

Negative depletion of blood cells is a promising alternative to marker-based positive selection of CTCs and has been used widely. Antibodies against CD45, expressed on almost all nonerythrocyte blood cells (Nakano et al., 1990), are used to capture and deplete leukocytes. However, as circulating endothelial cells are also $\mathrm{CD}^{4} 5^{-}$, false positive results may jeopardize the final enumeration (Alix-Panabieres and Pantel, 2014). Tumor specific markers such as HER2 and EGFR (Riethdorf et al., 2010) or tissue specific markers such as prostate specific antigen (PSA) (Miyamoto et al., 2012) and mammoglobin (Markou et al., 2011) can also prove to be good candidates but their utility might be downplayed by the fact that like all other markers, they show highly variable expression and their capture ability may be limited to specific subtypes of cancer.

Physical properties based CTC isolation approaches are rooted in the assumption that tumor cells differ considerably from hematologic cells in certain biomechanical and electrical characteristics such as size, deformability, buoyant density, dielectrophoretic mobility etc. Physical properties based label-free methodologies are able to, presumably, circumvent the biomarker heterogeneity related losses and provide unbiased CTC enrichment. Nonetheless, it 
has also been known that there is a considerable overlap between physical properties of CTCs and blood cells. For example, for several decades CTC research has been very stringent on considering cells only above $13 \mu \mathrm{m}$ to be CTCs. However, recent investigations suggest that cells below the usual size cut-off value of $10 \mu \mathrm{m}$ also demonstrate CTC behavior. CTCs as small as $4 \mu \mathrm{m}$ have been detected (Allard et al., 2004), much smaller than the pore sizes in routinely used membrane filters $(8-11 \mu \mathrm{m})$ leading to loss of a portion of CTC population (Cima et al., 2013). Inherent deformability of blood cells has also been exploited to make devices such as high pore density silicon microsieves (Lim et al., 2012) which isolate CTCs by virtue of their size and stiffness; deformable and smaller blood cells squeezing through the pores while larger and stiff CTCs are captured. Nevertheless, it has been demonstrated that malignant transformation of cells reduces stiffness remarkably; metastatic cells have $70 \%$ less stiffness as compared to benign cells (Cross et al., 2008). Epithelial to mesenchymal transformation also makes tumor cells more deformable, hence the risk of losing a valuable subpopulation of CTCs if size and deformability based filtration devices are used (AlixPanabieres and Pantel, 2014).

\subsection{Technical Challenges in Devising CTM Enrichment/Isolation Methods}

Macroscale or batch purification methods employed in early days of CTC research involve multiple processing steps which may lead to the disruption of CTM. Moreover, these devices have generally demonstrated low capture efficiencies, thus further limiting their applicability to CTM isolation. Given that CTM are made up of more than one cells and hence considerably larger than blood cells, filtration devices may be an effective option for CTM enrichment. The original polycarbonate filter membranes used in ISET $^{\circledR}$ (Vona et al., 2000) and ScreenCell ${ }^{\circledR}$ (Desitter et al., 2011) systems were manufactured by track-etching fixed sized pores randomly on membrane surface, which may result in fusion of pores leading to large variations in capture efficiency and sample clogging on filter surface (Cima et al., 2013). Although more recently microfabrication techniques have been employed to overcome this pore-fusion limitation (Hosokawa et al., 2013), filtration based isolation still suffers major shortcomings. Such as, with the cells being progressively trapped on membrane, hydrodynamic resistance of filter may change unpredictably causing deformation and eventual escape of trapped cells (Zheng et al., 2011). Additionally, continuous static pressure on trapped cells at pores may lead to cytoskeletal remodeling and cytoadhesion (Yap and Kamm, 2005). Finally, recovery of viable CTCs for subsequent molecular characterizations is particularly difficult from many filtration devices, thus further limiting their broad applicability (Dong et al., 2010). In addition to the 
aforementioned shortcomings, these filtration devices use high flow rates leading to high shear forces and hence may damage the clusters or cause them to squeeze through the pores, as recently modeled in a computer simulation (Sarioglu et al., 2015). Moreover, it has been observed that CTM containing up to 20 cells may adopt reversible single-file chain-like geometries which helps them traverse through 5-10 $\mu \mathrm{m}$ constrictions, a striking observation which may have implications in the usage of filtration based devices for CTM enrichment (Au et al., 2016).

Microfluidic technologies have proven utility in rare cell research, including CTCs, by virtue of the several advantages they offer, such as miniaturization, economic sample and reagent consumption, portability, immense design diversification capabilities, low cost, and faster sample processing times (Hejazian et al., 2015). Furthermore, low shear operation capability of microfluidics based platforms makes them specifically suitable for isolation of intact and viable CTM (Sarioglu et al., 2015). Nevertheless, microfluidic technologies also have inherent disadvantages such as considerable reduction in throughput under CTM favoring low shear operation conditions. Optimizing an appropriate shear rate in microfluidic devices which rely on marker-dependent CTC/CTM capture is particularly challenging, because a trade-off between purity and recovery rate seems inevitable. While higher shear rate may reduce capture efficiency, low shear conditions on the other hand may lead to increased non-specific WBC capture resulting in low purity (Wang et al., 2016). Marker dependent isolation of CTM, whether by macroscale approaches or microfluidic platforms, faces another challenge. CTM have low area to volume ratio thus reducing the surface available for antigen-antibody interaction, as compared to single CTCs. Therefore, marker-dependent CTM enrichment may lead to their underrepresentation (Fabisiewicz and Grzybowska, 2017).

\section{Methods for CTM Enrichment and Identification}

With the growing awareness that CTC clusters/CTM represent a unique hematogenous tumor cell population remarkably different from single CTCs and potentially a targetable entity for various clinical interventions, the need for specific and efficient CTM isolation technologies is being strongly felt. The majority of the methods used for CTM enrichment so far have actually been designed to capture single CTCs, and specific design and operational considerations required for efficient and reliable capture of CTM have seldom been taken into account (Sarioglu et al., 2015). Nonetheless, many batch purification techniques or microfluidic devices currently in use for CTC enrichment are capable of isolating CTM, albeit at remarkably 
lower sensitivities (Hong et al., 2016; Krebs et al., 2014; Sarioglu et al., 2015). The section below will highlight the existing technologies for CTM enrichment and identification further emphasizing their key features and performance attributes.

\subsection{Macroscale Approaches for CTM Isolation}

\subsubsection{Batch Purification Methods}

Batch purification methods such as density gradient centrifugation were among the earliest approaches used to isolate single CTCs (Seal, 1959). Likewise, Brandt et al.'s studies which used "combined buoyant density gradient and immunomagnetic cell separation" are one of the first recorded reports of CTM isolation from human blood (Brandt et al., 1996; Brandt et al., 1998). The said method depends on density gradient based separation of CTCs/CTM and leukocytes from bulk blood cell population followed by specific isolation of cancer cells/clusters by anti-cytokeratin antibodies attached to superparamagnetic microbeads (Brandt et al., 1996). The captured cell population is further labeled with biotinylated anti-CK8/18 and anti-PSA (prostate specific antigen) for Streptavidin-ALP based detection. Interestingly, in both studies clustered cancer cells were identified in more patients as compared to single cells (8/10 vs 6/10 prostate cancer and $24 / 29$ vs $13 / 29$ breast cancer patients). Another report by Wang et al. employed similar density gradient coupled to immunomagnetic separation strategy. However, instead of positive immunomagnetic isolation of cancer cell population, this method relied on depletion of WBCs by using magnetically labeled anti-CD45 antibodies (Wang et al., 2000). CTM made up of 3-100 cells were identified and remarkably were entirely composed of growing/living cancer cells, in contrast to a significant terminal single CTC population (Wang et al., 2000). Molnar et al.'s study used anti-CK 7/8 based immunomagnetic cell separation (without prior density gradient centrifugation step) followed by cytocentrifugation, pan anti-CK immunocytochemical labeling, and microscopic analysis (Molnar et al., 2001). Mix doublets, tumor cell clusters, or mixed clusters were found to be more frequent as compared to single CTC events in almost all of the 22/32 colorectal cancer patients, in which more than one $\mathrm{CK}^{+}$cells were identified (Table 1). This observation suggests that elimination of gradient centrifugation may favor enrichment of CTM (Molnar et al., 2001). A major limitation of these early methods is that they require large volumes of blood $(20-50 \mathrm{ml})$. Moreover, centrifugation based methods usually yield very low purity capture $(<1 \%)$ and their use has now been restricted to an initial enrichment step in advanced CTC isolation protocols.

\subsubsection{Isolation of CTM by ISET® and CellSearch ${ }^{\circledR}$}


Isolation by size of epithelial tumor cells (ISET ${ }^{\circledR}$, Rarecells diagnostics, Paris, France) is one of the well-known commercialized platforms. ISET $^{\circledR}$ device is made up of 10-12 wells

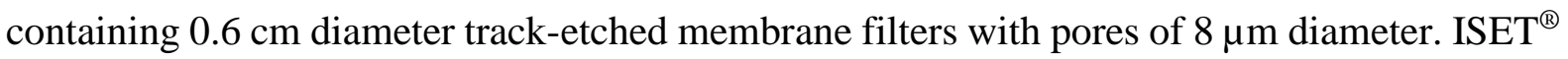
separates CTCs from blood cells in a size and deformability manner and CTM isolation has also been reported by this device in various studies (Hou et al., 2011; Vona et al., 2004; Vona et al., 2000). Although ISET $^{\circledR}$ based studies have contributed valuable insights into the biology and clinical relevance of CTM (Table 1), there are a number of shortcomings associated with this platform (discussed in detail in Section 3.3). Another commercial, and the only FDA approved CTC platform, CellSearch ${ }^{\circledR}$ (Veridex LLC, CA, USA), has also been instrumental in CTM research, however it exhibits even more limited capability for reliable detection of CTM as compared to $\operatorname{ISET}^{\circledR}$ (Allard et al., 2004; Hou et al., 2011; Hou et al., 2012; Khoja et al., 2012; Krebs et al., 2012). Possible causes of this limited ability may include dissociation of CTM due to prolonged manipulation or reduced effective magnetic attraction due to large size of CTM or shielding by non-EpCAM expressing CTM associated cells (Hong and Zu, 2013).

\subsubsection{CAM Assay}

Collagen adhesion matrix (CAM) assay (later commercialized by Vitatex, Inc., NY, USA) is based on the presumption that tumor cells in circulation are more invasive and hence may be able to invade a collagenous matrix more efficiently as compared to blood cells (Lu et al., 2010). A two-step protocol; Ficoll density gradient centrifugation to enrich mononuclear cells followed by adhesion of invasive cells to CAM coated wells of chamber slides, is used for CTC/CTM isolation. In castration-resistant prostate cancer patients, CTM were identified in $17 \%$ of the samples but their number did not correlate with the number of single CTCs per ml (Friedlander et al., 2014). It is important to note here that the CAM assay specifically favors the isolation of CTCs with collagen invasive phenotype, nonetheless live cells are isolated by this method which are suitable for a range of downstream molecular studies.

\subsubsection{Flexible Micro Spring Array Device}

Another high throughput microfiltration based device, Flexible micro spring array (FMSA), capable of isolating viable CTCs from $\sim 7.5 \mathrm{ml}$ of blood within 10 minutes achieved CTM enrichment from samples of various cancer patients (Harouaka et al., 2014). FMSA device is essentially a $0.5 \mathrm{~cm}^{2}$ microfabricated filtration device made up of Parylene $\mathrm{C}$ with an innovative micro spring geometry for filtration of CTCs/CTM from unprocessed blood samples, followed by anti-CK identification. FMSA device found CTM in $44 \%$ (7/16) of CTC 
positive samples from all types of cancer (breast, lung, colorectal). An important observation of this study was that around $35 \%$ of all CTCs occurred in clusters (Table 1). The device achieved $>90 \%$ capture efficiency, $10^{4}$-fold enrichment, and $>80 \%$ viability of recovered cells in cancer cell line spike-in experiments (for singlet CTCs).

\subsubsection{Immuno-Fluorescence in situ Hybridization (iFISH) Based CTM Detection}

Two recent reports have used a commercial cell separation method (Cytelligen, San Diego, CA, USA) in combination with iFISH for label-free enrichment and detection of CTCs/CTM. The "depletion/negative enrichment" method depends on centrifugation and cell separation matrix based depletion of RBC population followed by negative enrichment of cancer cell population by immunomagnetic depletion of WBCs by using a cocktail of multiple antileukocyte antibodies (Ge et al., 2015; Xu et al., 2017). CK18-iFISH was carried out for specific identification of CTCs while iFISH with antibodies against several other cancer markers were used for further phenotypic characterization and karyotyping (Ge et al., 2015). This method. exhibited high capture efficiency for all the cultured cell types tested (> $70 \%)$. Although no CTM identification from human cancer patient samples was reported, the authors detected CTM in human cancer xenograft mouse models and made striking observations regarding CTM biology. CTCs within CTM exhibited very heterogenous CK18 expression and were of sizes similar to those of WBCs (Ge et al., 2015). More recently Xu et al. applied similar strategy for CTC detection and enumeration based dynamic therapy response monitoring in prostate cancer patients (Xu et al., 2017). All the patients in which CTM were detected (6/40) had stage IV metastatic cancer. CTM detection was significantly correlated with reduced survival as compared to CTM-negative group as well as resistance to therapy (Xu et al., 2017).

\subsubsection{CellSieve CM $^{\mathrm{TM}}$}

CellSieve $^{\mathrm{TM}}$ is a photolithographically fabricated array patterned high porosity $13 \mathrm{~mm}$ microfilter (up to $\sim 160,000$ pores 5-9 $\mu \mathrm{m}$ in diameter, spaced $20 \mu \mathrm{m}$ from each other) (Adams et al., 2014).. A low-pressure vacuum assembly attached to the microfilter drives the size based isolation of CTCs. Using CellSieve ${ }^{\mathrm{TM}}$ Hayashi and colleagues reported detection of CTCs and CTM in sarcoma patients (Hayashi et al., 2017). As a marker independent method, CellSieve ${ }^{\mathrm{TM}}$ may prove to be useful for isolation of a CTM with variable phenotypes (Hayashi et al., 2017).

\subsection{Enrichment Free Methods for CTM Detection and Enumeration}




\subsubsection{Epic Platform}

High-speed automated immunofluorescent microscopy is among the most prominent enrichment free, or low-enrichment, methods for CTC/CTM enumeration (Cho et al., 2012; Marrinucci et al., 2012). This unbiased CTC detection method forms the basis of commercial Epic CTC Platform (Epic Sciences, Inc., San Diego, CA, USA) and employs $\mathrm{NH}_{4} \mathrm{Cl}$ based erythrocyte lysis followed by anti-CK/CD45/DAPI immunofluorescent staining. The method proved to be highly efficient and specific for CTM detection from clinical samples (up to 93 $\%$ of CTC positive stage IV prostate cancer patients and $0 \%$ healthy controls). Although this study reported an interesting observation that cancer cells comprising CTM, as well as their nuclei, are about the same size as that of WBCs, downstream molecular characterization of clusters identified by this method is challenging due to low purity (Cho et al., 2012; Sarioglu et al., 2015). Moreover, another limitation of this report was that only "homotypic" CTC aggregates/CTM could be characterized although "heterotypic" aggregates comprising of leukocytes and platelets in addition to cancer cells were observed and enumerated (Cho et al., 2012).

\subsubsection{Ensemble-decision Aliquot Ranking (eDAR)}

CTM have also been detected using another automated high throughput enrichment free CTC identification/enumeration system, namely eDAR (ensemble-decision aliquot ranking) (Schiro et al., 2012; Zhao et al., 2013). Unprocessed blood samples are labeled with fluorescent antibodies against CTC specific cell surface markers (e.g. EpCAM) which are subsequently introduced pneumatically through a microfluidic chip. Line-confocal detection system is used to specifically identify and enumerate target cells. Although the detection and enumeration part of this device is essentially enrichment free, isolation of CTCs/CTM for further analysis is achieved either through track etched polycarbonate membrane filtration (Schiro et al., 2012) or in the second generation eDAR device by microfabricated slits (Zhao et al., 2013). CTM capture was reported only using the second-generation device. The study reported that many of the CTM exhibited low EpCAM expression. The device is capable of high-throughput sample processing $(1 \mathrm{ml}$ blood$/ 12.5 \mathrm{~min})$ with $95 \%$ recovery and $0 \%$ false positive rate for single CTCs (Zhao et al., 2013). Furthermore, low hydrodynamic stress on cells helps maintain their viability for further analysis. A major limitation of the device is that it is incapable of direct and specific CTM detection and enumeration and it is only after the second purification step that CTM can be identified differentially from single CTCs. Moreover, complicated and costly set-up limits the widespread applicability of the device. Findings and applications of the enrichment free devices used for CTM detection and enumeration are presented in Table 2 


\subsection{Microfluidic Methods for Enrichment of CTM}

Advancements in microfabrication have enabled fabrication of devices/microfilters with controllable microenvironments, pore sizes, or flow chamber geometries and microstructures, and such platforms have already demonstrated their ability to overcome many of the challenges posed by batch purification approaches (Xavier et al., 2016). Recent advances in understanding of CTM biology and their potential role in cancer metastasis can largely be attributed to the development of these novel microfluidic devices. These low-shear operating high-throughput devices have made it possible to isolate viable and intact CTM from clinical samples suitable for further molecular and functional characterization (Sarioglu et al., 2015). However, despite their perceived promise, very few of the microfluidic devices have been used for CTM enrichment. To the best of our knowledge only two platforms have so far been developed with the specific aim to isolate CTM. Nonetheless, here we present a critical overview of all the microfluidics based methods used so far for CTM isolation with the aim to assist researchers in recognizing shortcomings and limitations of current platforms, a better understanding of which will ultimately help them to devise novel strategies and technologies for robust CTM isolation. A comparison of various performance characteristics of microfluidics CTM detection devices is presented in Table 3, while Table 4 summarizes the operational principles of all the microfluidic CTM devices as well as presents clinical applications and discoveries that these devices have enabled.

\subsubsection{Marker-Dependent Microfluidic Methods for CTM Enrichment}

\subsubsection{CTC-Chip}

CTC-Chip, developed about a decade ago, was among the first microfluidics based devices capable of CTM enrichment, and has since been used in various studies for efficient and highly selective isolation of single CTCs (Maheswaran et al., 2008; Nagrath et al., 2007; Stott et al., 2010b). CTC-Chip is a $25 \mathrm{~mm} \mathrm{X} 66 \mathrm{~mm}$ silicon chip, etched with an array of 78,000, $100 \mu \mathrm{m}$ tall and $100 \mu \mathrm{m}$ in diameter, microposts functionalized with anti-EpCAM antibodies (Figure 4A). Although the device has proven advantages over various batch purification methods used for single CTC enrichment ( 100\% yield, 49-67\% purity, viability of captured cells $>98 \%$ ) (Smirnov et al., 2005), the geometry of micropost arrangement presumably hinders the passage of CTM (Yu et al., 2011). Nonetheless, the device was able to capture CTM in PV (pulmonary vein) as well as peripherally drawn blood from 7 out of 20 CTC positive lung cancer patients 
(Reddy et al., 2016). However, the study didn't find any correlation between any clinical features and detection of CTM in patient blood.

\subsubsection{Herringbone-Chip}

One of the fundamental technical limitations of CTC-Chip was its reliance on laminar fluid flow through device under which only limited cell-substrate interaction is possible. Additionally, scaling up of the device production for routine clinical usage proved challenging due to the complex micropost structure. Keeping these limitations in view, Stott et al. adapted an earlier reported fluid-mixing in microchannels method (Stroock et al., 2002) and extended it to manufacture a novel CTC capture device (Stott et al., 2010a). This fluid-mixing method relies on generation of transverse flows in microchannels by placing oblique ridges at specific angles with respect to long axis thus inducing chaotic stirring in low Reynolds fluid flows (0 $<\operatorname{Re}<100)$ (Stroock et al., 2002). Herringbone Chip or HB-Chip utilizes herringbone shaped surface grooves created in the walls of the microchannel to generate microvortices thereby enhancing collision frequency between cells and antibody coated channel walls (Stott et al., 2010a). (Figure 4B). HB-Chip exhibited a capture efficiency of $\sim 79 \%$ at $1.2 \mathrm{mlh}^{-1}$ flow rate and could isolate viable CTCs. HB-Chip also proved capable of identifying CTM made up of 4-12 cells. 3D imaging of CTM verified their preserved shape and orientation thus excluding the possibility that these clusters arise due to "in-device" aggregation of single cells. The device was later used to successfully capture and analyze (RNA-seq and RNA in-situ hybridization) CTM from a pancreatic cancer mouse model (Yu et al., 2012).

With a slight modification in CTC capture principle, the device was also used in a subsequent study that not only provided the evidence of EMT in circulating breast tumor cells but also highlighted dynamic shifts between these cell types as a function of response to therapy (Yu et al., 2013). This modified device used by Yu et al. differed from the prototype HB-Chip in the way that microchannel walls were functionalized with a combination of three different antibodies; anti-EpCAM plus antibodies targeting lineage specific markers epidermal growth factor receptor (EGFR) and human epithelial growth factor receptor 2 (HER2). This strategy allowed capture of both epithelial and mesenchymal CTC populations, either as single CTCs or as part of CTM. Clusters of 4-50 CTCs were identified in an indexed patient, while those of 2-20 cells were identified in two additional patients. Remarkably, in index patient, appearance of CTM was directly related with increased mesenchymal phenotype CTCs while they were 
absent from specimens with predominant epithelial CTC phenotype. Large number of platelets was found to be associated with tumor cells in CTM (Yu et al., 2013).

\subsubsection{CTC-iChip}

Both CTC-Chip and HB-Chip devices require surface functionalization and hence yield CTCs immobilized to the device surface, which in turn makes further characterizations of captured cells extremely difficult. In an attempt to address these shortcomings, Ozkumur et al. developed a unique capture platform with three distinct microfluidics functions sequentially integrated in to one device. i) "Deterministic Lateral Displacement (DLD) based debulking of sample from RBCs, platelets, free magnetic beads, and other blood components like smaller cellular debris etc., ii) "Inertial Focusing" of debulked nucleated cells by introducing asymmetric curved channels in the laminar fluid flow path, and iii) immunomagnetic separation of CTCs ( ${ }^{\text {pos }}$ CTC-iChip, anti-EpCAM functionalized beads) or WBCs ( ${ }^{\text {neg }}$ CTC-iChip, antiCD45 and anti-CD15 functionalized beads) from the inertially focused nucleated cell population (Di Carlo, 2009; Huang et al., 2004; Ozkumur et al., 2013). Inertial focusing through a series of 60 asymmetric focusing units prior to magnetophoresis also helps to prevent the cellular collisions ensuring cellular displacement as a function of magnetic load only. General schematic of CTC-iChip is provided in Figure 4C.

Both versions of CTC-iChip exhibit high levels of capture efficiency ( ${ }^{\text {pos }} \mathrm{CTC}$-iChip 77.8-98.6 $\%$, ${ }^{\text {neg }}$ CTC-iChip 96.7-97.0). However, ${ }^{\text {pos }}$ CTC-iChip performed better than the ${ }^{\text {neg }}$ CTC-iChip mode in terms of sample purity (>3.5 log vs $2.5 \log$ purification). The capability of CTC-iChip to isolate cells in suspension has helped the researchers to carry out detailed cytopathological and immunocytochemistry analyses to ascertain cellular morphology and identity of all the non-hematological cells isolated. Of particular interest to the main theme of this review, the ${ }^{\text {neg }}$ CTC-iChip platform was able to identify clusters of 2-6 $\mathrm{CK}^{+} \mathrm{CTCs}$ in both breast and pancreatic cancer samples. Moreover, isolation of solution suspended CTCs/CTM enabled single cell RNA expression profiling, a feature which proved particularly useful in subsequent studies aimed at molecular characterization of CTM (Aceto et al., 2014; Ozkumur et al., 2013). In a monumental study Aceto et al. made use of both HB-Chip (or ${ }^{\mathrm{HB}} \mathrm{CTC}-\mathrm{Chip}$ ) and ${ }^{\text {neg }} \mathrm{CTC}$ iChip for delineating cellular origin, metastatic potential, and various other aspects of CTM biology in mouse model, as well as single-cell resolution RNA-seq analysis of breast cancer patient derived CTCs and CTM. ${ }^{\mathrm{HB}}$ CTC-Chip used by Aceto et al. was similar to the one used 
by $\mathrm{Yu}$ et al., in the way that channel walls were functionalized with a cocktail of 3 antibodies; anti-EpCAM, anti-EGFR, and anti-HER2 (Aceto et al., 2014).

Patterning the device surface with stimuli-responsive coatings has been used as an alternate to the enzymatic release of CTCs captured by antibody affinity. Under the influence of specific stimuli, such as temperature, these surface coatings undergo degradation thus facilitating and maximizing the release efficiency and post-release viability of CTCs. ${ }^{\mathrm{HB}} \mathrm{CTC}-\mathrm{Chip}$ with inner surface functionalized by a gelatin based nanostructured coating has reported capture efficiencies similar to prototype ${ }^{\mathrm{HB}}$ CTC-Chip, and release efficiency and viability as high as 93.2 \% and $88.3 \%$ respectively (Reategui et al., 2015). Use of streptavidin-coated nanoparticles in this device improves the capture efficiency of device up to 5-folds. Release of CTCs was achieved by dissolution of gelatin nanocoating either; by increasing temperature of device from room temperature to physiological temperature $\left(37^{\circ} \mathrm{C}\right)$ for release of bulk CTC population, or through shear stress produced by vibration generating microtip across a tunable radius for selective removal of single cells. When applied to CTC/CTM analysis on blood samples from a small cohort of cancer patients, this surface modified ${ }^{\mathrm{HB}} \mathrm{CTC}$-Chip identified CTM of $\geq 4$ cells in $37.5 \%$ breast and $25 \%$ lung cancer subjects (Reategui et al., 2015).

Even though both HB-Chip (or ${ }^{\mathrm{HB}}$ CTC-Chip) and CTC-iChip made valuable contributions to our understanding of clinical significance and biology of CTM, flow conditions in these devices primarily favor single CTC isolation and a substantial number of CTM may undergo disruption. An ideal device for CTM isolation may employ channel geometries and optimized flow conditions and shear forces that favor specific separation of CTM. Furthermore, given the heterogeneity of surface marker expression and cellular types within a CTM, the devices should be able to capture a broad range of CTM unbiasedly.

\subsubsection{OncoBean Chip}

One of the biggest challenges in affinity-based liner flow microfluidic devices is the relatively low flow rates. Most of the microfluidic devices reported so far, particularly the ones employed for CTM isolation, operate at flow rates of 1-3 $\mathrm{mlh}^{-1}$. High shear associated with high flow rates not only reduces antigen-antibody interaction but may also lead to disintegration of CTM. High throughput is a critical factor from the standpoint of clinical application where processing of large sample volumes and numbers may be required. To address this challenge, Murlidhar and colleagues developed a radial flow microfluidic CTC capture device OncoBean Chip (Murlidhar et al., 2014). The OncoBean Chip consists of $50 \mu \mathrm{m}$ wide and $118 \mu \mathrm{m}$ along the 
longest axis, antibody coated, bean shaped microposts with an arc angle of $90^{\circ}$. Individual microposts are placed 25-32 $\mu \mathrm{m}$ apart in polar arrays. The OncoBean Chip is capable of operating at flow rates of $10 \mathrm{mlh}^{-1}$ at the same time maintaining high capture efficiency $(82.7 \%$ at $10 \mathrm{mlh}^{-1}$ compared to $90.7 \%$ for a standard CTC-Chip at $1 \mathrm{mlh}^{-1}$ ) (Murlidhar et al., 2014). More recently prognostic significance of measuring CTM in pulmonary (PV) as well as peripheral $(\mathrm{Pe})$ vein blood specimens from early stage lung cancer patients was demonstrated (Murlidhar et al., 2017). While larger CTC clusters were observed in PV blood ( $2->200$ cells) compared to Pe blood (2-9 cells), detection of CTM in preoperative Pe blood specimens predicted poor patient outcome. Detailed gene expression analysis of isolated CTCs/CTM shed important light on CTM biology, their higher metastatic potential, as well as molecular signatures which may be responsible for increased resistance of CTM to therapy (see section 2.6 for more details) (Murlidhar et al., 2017).

\subsubsection{3D Scaffold Chip}

Various approaches have been developed over the years to improve capture efficiency of marker-dependent CTC enrichment microfluidic devices. Disrupting laminar flow to increase contact frequency between cells and antibody-functionalized surfaces (Stott et al., 2010a), or enhancing topological interaction between cells and substrates by incorporation of nanoscale structures into the substrate surface (Lu et al., 2013) are among the prominent strategies to this end. Three-dimensional poly(dimethylsiloxane) scaffold chip, or "3D Scaffold Chip" in short, achieved high efficiency capture of CTCs and CTM by combining two strategies; spatially distributed macroporous structure generates chaotic migration of cells thus increasing mixing while nanorough surfaces of scaffold enhance binding between cells and antibodies. (Cheng et al., 2016). A 3D macroporous PDMS scaffold was generated by using Ni foam as sacrifice template. When integrated into a microchip, macropores of the scaffold serve to generate chaotic cell migration while nanostructures on its surface provide enhanced local topological interactions (Figure 4D). Anti-EpCAM functionalized 3D scaffold chip demonstrated a $92 \%$ capture efficiency for PBS suspended MCF-7 cells at a flow rate of $100 \mu 1 / \mathrm{min}$. Using only 1 $\mathrm{ml}$ of whole blood, CTM could be detected in 5 patients (1-14 CTM/ml) (Cheng et al., 2016). To facilitate the release of captured cells/clusters, the same group of researchers have recently introduced gelatin hydrogel coated 3D scaffold chip. Gelatin hydrogel is thermosensitive and melts at physiological temperature $\left(37^{\circ} \mathrm{C}\right)$ thus enables easy retrieval of viable CTCs/CTM that are suitable for a range of downstream molecular analyses (Cheng et al., 2017).

\subsubsection{CMx Platform}


Release of viable CTCs from affinity-based capture platforms is challenging. Routinely used methods like enzymatic digestion and high-shear reverse flow are known to damage cells (Adams et al., 2008), alter gene expression (Kang et al., 2008; Wang et al., 2005), and may particularly be unsuitable for recovery of intact and viable CTM. Chen et al. introduced a novel approach for easy cell/cluster release by coating the microfluid channel surface with "supported lipid bilayer" (SLB). Coating of the device with anti-EpCAM conjugated SLB supposedly provides "non-fouling" surface which reduces non-specific interactions between cells and the channel walls thus minimizing the shear force required to detach captured cells (Chen et al., 2016). Furthermore, interactions of SLB hydrophilic lipid molecule head groups with glass surface can be easily disrupted by introduction of air bubbles thus enabling easy release of CTCs/CTM without dissociating cell-antibody binding. "Cells captured in Maximum" (CMx) platform described in this study was made up of a $76 \mathrm{~mm}$ X $25.4 \mathrm{~mm}$ X $1.5 \mathrm{~mm}$ poly(methyl methacrylate) (PMMA) chip bonded to a glass slide, inner walls of which were coated with anti-EpCAM conjugated SLBs. CMx chip also incorporated various laser scribed micropatterns and after performance testing a four-channel microfluidic device with alternate permutation linear micropatterns was finally selected for further experiments (capture efficiency $93.7 \pm 8.9 \%$ ).

The device operation consists of three steps; capture of CTCs by flowing $2 \mathrm{ml}$ of blood through the microchannel at a rate of $1.5 \mathrm{mlh}^{-1}$ (Figure 4E, left), in second step washing with buffer at increased flow rate is used to remove cells bound non-specifically to surface, and finally disruption of SLB assembly by gentle air sweep to release viable CTCs/CTM (Chen et al., 2016). Gentle air sweep release strategy (Figure 4E, right) not only proved to be very efficient ( $99.7 \%$ in 3 repeats), $86 \%$ of the released cells were viable. Furthermore, close to $100 \%$ capture efficiencies and recovery rates for CTM were achieved highlighting the platform's usefulness for isolation of intact and viable CTM. This system effectively isolated large number of CTM from $2 \mathrm{ml}$ of blood, with mean and median as high as 71.7 and 60 respectively in stage IV CRC patients. The study also highlighted the fact that CTM count is better able to distinguish various stages of CRC from each other, as compared to CTC count; sensitivity, specificity, and positive detection rate of CTM to distinguish CRC patients from healthy subjects were $67 \%, 89 \%$, and 97\% respectively (Chen et al., 2016). CMx platform was also used to demonstrate the significance of CTM as an independent prognostic marker in Pancreatic Ductal Adenocarcinoma (PDA) patients (Chang et al., 2016). A mean of 29.5 CTM per $2 \mathrm{~mL}$ of blood were detected in $81 \%$ of the patients and the number of CTM appeared to be correlated with 
disease stage. Remarkably, patients with CTM > 30 per $2 \mathrm{~mL}$ had significantly shorter progression free as well as overall survival compared to the patient group with CTM $<30$ per $2 \mathrm{~mL}$, thus highlighting the applicability of CTM as independent prognostic marker (Chang et al., 2016).

Antibodies for CTC capture are immobilized to substrate/device surface via neutravidin-biotin like conjugations, with biotin linked randomly to one or more of $~ 90$ lysine groups spread all over the antibody surface. However, this random linkage of biotin to antibodies may orient antibodies during attachment to substrate in a way where access of CTCs to Fab domain of antibody is hindered thus reducing overall device capture efficiency. Recently it has been demonstrated that by introducing site-specific attachment of linker group to Fc domain of antibodies which preferentially favors upward facing of Fab domain, CTC and CTM capture efficiency of CMx device, from CRC pateints, can be increased by $\sim 1.6 \mathrm{x}$ and $\sim 3 \mathrm{x}$ respectively (Lai et al., 2017).

\subsubsection{Microfluidic Devices for Label-Free Isolation of CTM}

Ample evidence exists to suggest that unbiased physical characteristics based CTC enrichment technologies outperform antigen-dependent methods in terms of sensitivity and may in fact be particularly useful for CTM isolation (Krebs et al., 2012). Therefore, despite low capture purity various marker-independent batch purification and microfluidic based methods have been used to isolate CTM.

\subsubsection{Microcavity Array}

Among the first microfluidic platforms that isolated CTM in label-free manner was a sizeselective microfilter integrated into a microfluidic device, the so-called microcavity array (MCA) system which employed an array of 10,000 size and geometry controlled microcavities for CTC/CTM entrapment (Figure 5A) (Hosokawa et al., 2013). For single CTCs, MCA system showed 68-100\% capture efficiency, significantly better than ISET $^{\circledR}$ platform, and a sensitivity of 1 tumor cell per $7.5 \mathrm{ml}$ of blood. The system's major strength lies in its precisely controlled alignment of captured CTCs/CTM and contaminating leukocytes onto the microcavities, which simplifies downstream automated fluorescent microscopy based identification. Furthermore, the integration of MCA with a microfluidic device enabled on chip post-processing of captured cells. Contiguous groups of 3 or more nuclei, defined here as CTM, were also observed to have individually retained on microcavities. The device also exhibited a higher detection sensitivity 
as compared to CellSearch ${ }^{\circledR}$ in CTC enumeration from metastatic lung cancer patients (Hosokawa et al., 2013).

\subsubsection{Spiral Biochip and Vortex Chip}

Manipulation of hydrodynamic forces offers a labeling- and external-force-free strategy to sort cells in microfluidic settings. Particles with Reynolds numbers upwards of 1 experience two counteracting inertial lift forces $\left(\mathrm{F}_{\mathrm{L}}\right)$ while moving in laminar microfluidic flows. These inertial lift forces include; shear induced lift force which pushes the particles towards channel walls, and wall effect that repels the particles away from the walls. Combined effect of these two opposing forces leads to the lateral migration of particles in microfluidic flows until the particles reach an equilibrium position between the center of channel and its walls (Di Carlo et al., 2007; Segre and Silberberg, 1962a, b). Not only that these intrinsic inertial forces can be manipulated by altering parameters like channel and particle diameters, and flow rate, thus facilitating focusing of particles to precise controllable 3D locations within the channel (inertial focusing), by introducing secondary flows or disruptions in laminar flow, particles in these focused continuous streams can be separated from each other based on their sizes. (Di Carlo et al., 2007). This hydrodynamic manipulation has served to create various bioparticle separation and focusing devices including CTC enrichment platforms (Choi et al., 2011; Kim et al., 2014; Russom et al., 2009). Among these various inertial focusing based CTC enrichment methods, at least two have been used for CTM isolation.

In curvilinear channels, e.g. spiral channels, an additional centrifugal force called "Dean drag force" $\left(F_{D}\right)$ also acts on particles. As such exact three-dimensional positioning of particles in a curvilinear channel is dependent upon the ratio of $\mathrm{F}_{\mathrm{L}}$ and $\mathrm{F}_{\mathrm{D}}\left(\mathrm{F}_{\mathrm{L}} / \mathrm{F}_{\mathrm{D}}\right)$, which in turn is proportional to the third power of particle diameter (Esmaeilsabzali et al., 2013; Kuntaegowdanahalli et al., 2009). By manipulating the interplay of these forces, Hou et al.'s proposed method "Dean Flow Fractionation", achieved high throughput size based focusing of CTCs to precise controllable locations along the microchannel wall (Hou et al., 2013). Channel height $(160 \mu \mathrm{m})$ is adjusted such that only larger cells, CTCs, satisfy the $\mathrm{a}_{\mathrm{p}} / h>0.1$ criteria $\left(\mathrm{a}_{\mathrm{p}}\right.$ $=$ particle diameter and $h=$ microchannel height $)$ and hence experience $\mathrm{F}_{\mathrm{L}}$ while the smaller RBCs and WBCs do not. A sheath fluid (1x PBS) is pumped through the inner inlet to keep the blood, pumped through outer inlet, pushed against the outer channel wall (Figure 5B). As the cells move along "Dean vortices" and migrate towards inner wall, strong inertial lift forces confine CTCs to inner wall while smaller blood cells continue to be entrained along dean vortex 
flow (Hou et al., 2013). This way CTCs and blood cells are focused to distinct streams within the microchannel and can be collected through two separate outlets (Figure 5B). With > 85\% demonstrated recovery (spiked-in cell line experiment), the "Spiral Biochip" was able to capture 5-88 CTCs/ml in 100\% samples obtained from metastatic lung cancer patients.

Regarding the device's ability to capture CTM, the authors claimed to have isolated in vitro generated MCF-7 clusters as well as CTM from one patient's blood. It was suggested that despite high flow rate, short transit time through the channel prevents cluster disruption. However, in addition to the inevitable loss of CTCs smaller than $10 \mu \mathrm{m}$, a major shortcoming of the device was inadequate removal of RBCs due to dispersions induced by cell-to-cell interactions. In an attempt to further mitigate this issue as well as improve the throughput of device, two alterations were later introduced to both protocol and the device design; an RBC lysis step prior to sample processing at biochip, and a multiplex device made up of 3 spiral sorters with common inlets and outlets joined in parallel (Warkiani et al., 2016). Nucleated cells after RBC lysis were resuspended in saline to achieve a final volume $0.5 \mathrm{X}$ of original blood sample volume thus improving device throughput as well as reducing RBC contamination. These two alterations significantly improved the throughput of $2^{\text {nd }}$ generation spiral chip ( $7.5 \mathrm{ml}$ in $12.5 \mathrm{~min}$ vs $3 \mathrm{ml} / \mathrm{h}$ ). With recovery rate ( $\geq 85 \%$, spiked-in cell lines) and detection sensitivity ( $\sim 100 \%$, patient samples) comparable to its earlier version, multiplex device offered a clear advantage in terms of throughput without compromising other parameters. Above all, the spiral biochip was also able to retrieve CTM from blood samples. Although both reports did not venture beyond reporting successful isolation of CTM, device's ability to generate tight size based focusing of cells makes it a promising candidate for CTM retrieval studies. The analytical model presented by Warkiani et al. can potentially be used to calculate flow rates as well as channel and inlet/outlet split dimensions that specifically favor CTM isolation (Warkiani et al., 2016). More recently, the device has been used to enumerate CTM in head and neck cancer patients where more than half of the CTC+ patients were found to have CTM in their blood (Kulasinghe et al., 2017).

Separation of inertially focused particles in laminar flows has also been achieved by introducing multiple expanding reservoirs in fluid flow path. As the tightly focused particle streams enter the expanding reservoirs, wall effects become negligible leaving shear induced lift force as the dominant effective force pushing particles away from channel center. Larger particles like tumor cells/clusters are thus forced to move in vortices while smaller blood cells continue along their laminar paths (Sollier et al., 2014). Vortex chip consists of 8 parallel 
channels $\left(\mathrm{H}=80-85 \mu \mathrm{m}, \mathrm{W}_{\mathrm{C}}=40 \mu \mathrm{m}, \mathrm{L}_{\mathrm{C}}=4 \mathrm{~mm}\right)$, with 8 reservoirs each in series per channel $\left(\mathrm{W}_{\mathrm{R}}=480 \mu \mathrm{m}, \mathrm{L}_{\mathrm{R}}=720 \mu \mathrm{m}\right)$ (Figure 5C). As the sample enters the channel, randomly distributed cells migrate to equilibrium positions Xeq under the influence of two opposing lift forces; wall effect $\left(F_{L W}\right)$ and shear force $\left(F_{L S}\right)$. As the sample enters the reservoir, CTC/CTM which experience larger $F_{L S}$ due to bigger sizes move away from channel center due to reduction in wall effect and move in vortices and are hence stably trapped in reservoirs. On the other hand, smaller blood cells continue to move along the main flow (Figure 5C). Prominent strength of vortex chip is the high purity (57-95\% for clinical samples) and close to $90 \%$ viability (spiked-in cancer cell lines) of captured CTCs. Moreover, the device is capable of processing blood samples at very high throughput; $7.5 \mathrm{ml}$ of whole blood (10x diluted) in 20 minutes, at $4 \mathrm{mlmin}^{-1}$ flow rate, and its capture efficiency is independent of a pre-processing $\mathrm{RBC}$ lysis step further reducing processing time.

However, capture efficiency of vortex chip is strongly dependent on size and deformability of the particles/cells. Capture efficiency for cells close to the cutoff size of $15 \mu \mathrm{m}$ was as low as $7 \%$. Even for cells of larger sizes, maximum capture efficiencies were slightly more than $20 \%$ highlighting the major shortcoming of the device. Furthermore, as deformable particles experience an additional lift force in microfluidic flows which pushes the particles more towards channel centerline and affects their inertial focusing (Hur et al., 2011), more deformable cancer cells are captured with reduced efficiencies (Sollier et al., 2014). Although the authors did report observing CTM in cancer patient samples, further enumeration or characterization was not carried out. As a label-free method capable of isolating CTCs/CTM with very high ratio of viability as well as purities, vortex chip appears to be a useful candidate for further developments in isolating CTM for downstream molecular characterizations. However, extremely low capture efficiency appears to cast doubts on its usefulness for studies aiming to explore clinical utility of CTM enumeration.

\subsubsection{Microfluidic Chip with Triangular Pillar Array and Filter Channel Array}

Recently Gao et al. modified an earlier reported size based CTC isolation technology (Huang et al., 2014), which not only improved the device performance but also helped in sequential capture of CTM and CTC separately (Gao et al., 2016). The earlier version of device made use of a series of alternating and parallel microchannels; main channel and side channel, connected to each other through an array of filter channels at regular intervals. Main channels are connected to an inlet from where the sample is injected using syringe pump while their far end 
is connected to the outlet through a narrow filter channel $(20 \mu \mathrm{m} X 2-8 \mu \mathrm{m})$. On the other hand, leading ends of side channels are blind, therefore entry to the side channels is only through filtration channels. When negative pressure is applied at the outlet, the pressure difference between main and side channels directs sample flow through the filtration channels from main to side channels. This way, smaller sized blood cells flow through narrow filtration channels to the side channels and ultimately to outlet while larger CTCs are trapped inside the main channels (Huang et al., 2014).

Modified filter channel array, or single cell filtration area, in Gao et al.'s report is made up of 30 main $(80 \mu \mathrm{m}$ X $50 \mu \mathrm{m})$ and 31 side $(50 \mu \mathrm{m}$ X 50 $\mu \mathrm{m})$ channels interconnected through an array of $40 \mu \mathrm{m} X 10 \mu \mathrm{m}$ filter channels. Upstream of the single cell filtration area, bulk filtration area made up of an array of triangular microposts is connected to the inlet through branched pipelines. Basic unit of triangular micropost array is made up of 3 triangle pillars similar to the cluster-chip device discussed below (Sarioglu et al., 2015). However, this bulk filtration area is made up of two successive sub-regions of variable narrowing channel widths; $1^{\text {st }} 50 \mu \mathrm{m}, 2^{\text {nd }}$ $20 \mu \mathrm{m}$. As the sample enters through inlet to the bulk filtration area, single cells (CTCs or blood cells) pass through these narrow channels while CTM and other bulk contaminants are trapped at the leading edge of triangular micropost. Single CTCs are subsequently separated from blood cells in single cell filtration area for subsequent identification and characterization. Although the device appears to be highly efficient; throughput $15 \mathrm{mlh}^{-1}$, recovery efficiency $>94 \%$, for isolating single CTCs, it's performance regarding CTM capture is not known. Nonetheless, CTM of more than 3 cells were successfully captured in bulk filtration area from the blood of lung cancer patients.

\subsubsection{Cluster-Chip}

Cluster-Chip is the first ever microfluidics based device designed with the specific aim to capture CTM from unprocessed blood (Figure 5D). Basic unit of the Cluster-Chip device, the "cluster trap", is a set of three triangular pillars. Two of the triangular pillars in this unit are positioned parallel to each other with their edges facing forward. A gap of defined length between them makes a funnel shaped channel narrowing down towards their bases, where the edge of third pillar forms a furcation. After passing through this narrowing channel, the laminar flow path of fluid is bifurcated into two streamlines at the edge of third pillar. Each of the streamlines passes through an opening of $12 \mu \mathrm{m}$ X $100 \mu \mathrm{m}$ after bifurcation thus carrying with it single blood and cancer cells. Edge of bifurcating (third) pillar serves as a fulcrum where 
cell-to-cell junctions provide a stable equilibrium between various forces acting on cluster (drag force due to fluid flow, reaction forces from pillars, and frictional forces including cellular adhesion), thus irrespective of their deformability clusters are retained at the bifurcating edge. Sample introduced from a single inlet is distributed uniformly to 4,096 parallel tracks, each composed of seven consecutive rows of cluster traps, and the waste is collected through a single outlet. For Cluster-Chip, the cumulative flow cross section at bifurcation nodes is $\sim 10 \mathrm{~mm}^{2}$. One of the remarkable features of cluster-chip is that flow speed is kept well below the physiological flow speed experienced by clusters in capillaries (peak flow speed $\sim 70 \mu \mathrm{m} / \mathrm{s}$ at bifurcation), thus avoiding dissociation of clusters from traps due to high shear forces. Despite such a low flow speed, the chip could operate at an overall rate of $2.5 \mathrm{mlh}^{-1}$ due to highly parallel architecture.

Single and clustered cells spiking experiments revealed specificity of the device as no single cells were found to be retained. Although the cluster-chip exhibited very high capture efficiency for CTM made up of $\geq 4$ cells (99\%), substantially reduced efficiencies were observed for smaller clusters; $70 \%$ for 3 cell clusters, only $41 \%$ for 2 cell CTM. Remarkably, more than $95 \%$ of the captured CTM were found in first row indicating that the optimized flow rate caused minimum damage to their integrity. In comparison, $5 \mu \mathrm{m}$ filter membrane not only requires dilution of blood prior to CTM enrichment step, even at pressure 15 times lower than the routine pressure used in filtration ( 0.1 vs 1.5$)$, a maximum of $26 \%$ capture efficiency for CTM could be achieved by membrane. Efficiency of Cluster-Chip was $50 \%$ and $400 \%$ higher than the marker dependent HB-Chip for high EpCAM expressing MCF-7 and low EpCAM expressing MDA-MB-231 clusters, respectively. For a third cell line, MCF10A-LBX1, in which EpCAM expression is virtually absent, HB-Chip understandably could not capture any clusters at all. In comparison, Cluster-Chip exhibited 1,000-fold differential capture efficiency, thus demonstrating the suitability of this device to isolate CTM with a broad range of phenotypes.

Although release of captured CTCs/CTM from marker-independent devices for further analysis is relatively easy as compared to antigen-dependent ones where cells are tethered to antibodies, releasing CTM captured in Cluster-Chip is particularly challenging. At room temperatures, even at reverse flow rates as high as $250 \mathrm{mlh}^{-1}$, only $37 \%$ of the CTM could be released. However, reducing operating temperature to $4{ }^{\circ} \mathrm{C}$ can increase the release efficiency to $80 \%$ at reverse flow rate of $250 \mathrm{mlh}^{-1}$. Notably, decreased temperature also helped to maintain cell viability under these high reverse flow conditions, and seemed to reduce non-specific binding 
by leukocytes by as much as 50-fold. The device was subsequently used to isolate CTM from breast, melanoma, and prostate cancer patients' blood samples. A 4ml sample of patient blood was directly processed on Cluster-Chip and captured CTM were identified by immunofluorescence staining with anti- cancer specific marker antibodies as well as antileukocyte marker CD45. CTM made up of 2-19 cells were successfully detected in $~ 30-40 \%$ cancer patients with numbers ranging from $\sim 0.15 / \mathrm{ml}$ to $\sim 0.5$ clusters $/ \mathrm{ml}$. Interestingly, there was no correlation between the number of single CTCs (using CTC-iChip) and number of CTM captured from same samples. Thus, to summarize, Cluster-Chip exhibited a high level of specificity and efficiency in label-free isolation of CTM of a broad range of phenotypes from unprocessed patient blood. High level of cluster integrity, cell viability, and release efficiency enabled researchers to carry out in depth molecular characterization (Sarioglu et al., 2015).

\subsubsection{Deterministic Lateral Displacement Based Two-stage Continuous Flow Device}

The latest addition to this series of microfluidics based devices designed by Toner group is a continuous flow device pivoted on the Deterministic Lateral Displacement (DLD). This next generation cluster-chip device incorporates array of asymmetric hybrid micropillars in tandem with an array of cylindrical micropillars to accomplish a two-stage size and asymmetry based CTM sorting (Au et al., 2017). First stage of this device sorts larger CTM from blood cells, CTCs and smaller CTM based on size and is made up of an array of $90 \mu \mathrm{m}$ high micropillars positioned $63 \mu \mathrm{m}$ apart and with a 1/7 row shift ratio. Ceiling height of $90 \mu \mathrm{m}$ favors alignment of longitudinal axes of cells and small clusters $(<30 \mu \mathrm{m}$ in diameter) vertically, therefore the size based sorting in first stage is dependent only on the transverse axis. Larger CTM with effective transverse diameter $\geq 30 \mu \mathrm{m}$ are thus deflected to the stage 1 product stream while the remaining CTM, CTCs and blood cells continue to flow towards second stage of device. Stage 2 of the device separates asymmetric CTM from symmetric single cells by employing innovative hybrid I-shaped/elliptical micropillars. These "I" shaped grooves and ellipsoidal pillar asymmetries induce rotation in asymmetrical particles (like small CTM) and disrupt streamline symmetry respectively. Combined with reduced ceiling height $(30 \mu \mathrm{m})$, streamline disturbances induced by stage 2 micropillar design force small clusters to align their longitudinal axes along a continuum of angles relative to the direction of fluid flow that facilitate DLD deflection of these smaller CTM.

This proof of concept study used clusters obtained from in vitro suspension culture of breast cancer patient derived CTM to evaluate performance metrics of the device. The device appears 
to favor capture of larger clusters ( $\geq 9$ cells) as at a flow rate of $0.5 \mathrm{mlh}^{-1}, \sim 99 \%$ of clusters spiked in healthy blood samples can be captured. On the other hand, about $1 / 3^{\text {rd }}$ of the clusters smaller than 9 cells flow through to waste without being captured. Nonetheless, $>4 \log _{10}$ depletion of RBCs and up to $2.5 \log _{10}$ WBC depletion yields a level of capture purity suitable for direct imaging and analysis of CTM. Furthermore, peak shear stress experienced by clusters in the device (4.8 Pa) is well below the shear stress in normal human blood flow (5-20 Pa) thus enabling clusters to evade dissociation. Continuous flow operation of device makes isolation of CTM easier as no discreet release steps are involved, a feature that ostensibly favors post isolation viability and proliferation of CTM. More than $90 \%$ of the CTM captured by this device were found to be viable even at a flow rate of $1.0 \mathrm{mlh}^{-1}$. Despite the promising performance with respect to capture efficiency, purity, and post capture cluster viability, the device operates at low throughput. At the optimum flow rate of $0.5 \mathrm{mlh}^{-1}, 15$ hours would be required to process a $7.5 \mathrm{ml}$ blood sample. However, design and process modifications, such as parallelization or concentrating blood samples prior to processing on device, may help in achieving better throughput (Au et al., 2017).

\section{Ex Vivo CTC Culture: An Emerging Niche in Precision Oncology}

The inability to obtain sufficient cell numbers with minimal blood-cell background has been a major impediment in realizing the clinical potential of CTM. Thus, recent progress in the field has laid emphasis on in vitro expansion of CTC numbers from patients to retrieve molecular information and develop novel drug testing models. Immunosuppressed mice have been explored as incubators for expansion of CTCs, however use of animal models not only involves longer times and higher costs, efficiency of establishing tumors by inoculating CTCs into the mice is also very low (Khoo et al., 2017). On the other hand, ex vivo CTC culture may also provide a useful resource to establish robust personalized drug evaluation platforms and to monitor evolving patterns of drug susceptibility (Khoo et al., 2016; Yu et al., 2014). Initial attempts to this end involved use of CTCs isolated from mice xenografted with immortalized cancer cell lines to demonstrate the capability of various CTC enrichment devices to isolate viable cells. Successful ex vivo culture of human breast and lung cancer cell lines isolated from orthotopic mice as well as mouse mammary tumor cell line 4T1 from mice bearing implantable 4T1 breast tumors have been demonstrated (Ameri et al., 2010; Kang et al., 2012; Yu et al., 2014). Several studies have subsequently demonstrated short-term (3-14 days) culture of CTCs isolated from patients (Bobek et al., 2014a; Bobek et al., 2014b; Cegan et al., 2014) or spiked- 
in cancer cell lines (Chen et al., 2016; Sheng et al., 2014). In one such study, CTC isolated from lung cancer patients using a designated CTC-Chip were co-cultured with cancer associated fibroblasts in a three dimensional extracellular matrix consisting of collagen and Matrigel ${ }^{\circledR}$ (Zhang et al., 2014). In addition to delineating the culture conditions required for efficient expansion of patient-derived CTCs ex vivo, the study also characterized several molecular and phenotypic characteristics of expanded CTCs. The study revealed concordance of mutations in various cancer related genes between primary tumors and expanded CTCs, intratumor heterogeneity, and above all a direct correlation between the capacity of CTCs to expand ex-vivo and the recurrence and outcome in corresponding patient (Zhang et al., 2014).

In contrast to short-term CTC cultivation, their long-term culture for the establishment of cell lines is difficult and requires specialized conditions and additional supplements for growth (Khoo et al., 2017). In one of the first reports on long-term CTC culture, Zhang et al. used various mediums at different stages of growth to expand FACS isolated CTCs; stem cell culture medium for the first week, medium for epithelial cells up until day 21, and DMEM/F12 from day 22 onwards (Zhang et al., 2013). The study successfully established cell lines from EpCAM(-) CTCs obtained from 3 of the metastatic breast cancer patients. In contrast, $\operatorname{EpCAM}(+)$ cells did not survive beyond day 14. In another pioneering study, Yu et al. isolated CTCs using CTC-iChip and successfully maintained 6 lines of CTCs derived from ER(+) breast cancer patients for more than 6 months. The study demonstrated that addition of epidermal growth factor (EGF) and basic fibroblast growth factor (FGF) into the serum free media, coupled with hypoxic environment $\left(4 \% \mathrm{O}_{2}\right)$ provide the best conditions for long term proliferation of CTCs as tumor spheres (Yu et al., 2014). It has also been observed previously that CTCs grow more aggressively as colonies compared to their parent cell lines under chronic hypoxic conditions. (Ameri et al., 2010). Notably, Yu et al., showed that for long-term propagation, CTCs should be grown in non-adherent conditions as they senesce after a few cell divisions in adherent cultures (Yu et al., 2014). Similarly, long term cultures derived from colon cancer patients have been maintained for more than a year under nonadherent conditions (Cayrefourcq et al., 2015).

Three dimensional organotypic cancer models (organoids) have gained prominence in recent years. Organoids are the miniaturized versions of tissues grown in 3D biomimetic scaffolds like Matrigel® along with several niche factors required for the optimal growth of specific tissues (Neal and Kuo, 2016). Organoids derived from primary tumor tissues (Sato et al., 2011) as well as metastatic lesions (Weeber et al., 2015) have been developed. Gao et al. for the first 
time developed cancer organoid lines using CTCs isolated from prostate cancer patients (Gao et al., 2014). Organoid cultures developed from CTCs isolated using RosetteSep ${ }^{\mathrm{TM}}$ Human CD45 Depletion Cocktail combined with Ficoll-Paque density gradient media were maintained for more than 9 months (Gao et al., 2014). Although the aforementioned approaches have highlighted several prominent features of CTC-derived cultures, most importantly the high level of phenotypic and molecular and similarity between the cell lines and parent tumors, their integration to routine clinical practice has proved to be challenging. Further, most of the current CTC enrichment/isolation approaches developed are not particularly suited for downstream CTC culture. While release of viable cells from antibody-based capture platforms is challenging, label-free approaches are marred by low capture purity. On the other hand, long processing times and shear stress under high flow rate conditions may also compromise the viability and proliferative capacity of isolated CTCs (Khoo et al., 2017). More recently, a specialized assay for culturing of patient-derived CTCs without the need for pre-enrichment has been reported (Khoo et al., 2016). The microfluidic platform developed by Khoo et al. integrates a culture component, comprised of custom patterned inverted dome-shaped elliptical microwells, with a gradient generator component for in situ anticancer drug evaluation. RBC depleted blood samples are introduced to the culture component and CTCs along with WBCs are trapped in the wells where both the cell types are co-cultured and are subsequently expanded as CTC clusters. The gradient generator component on the other hand is made up of tree-like branched features to facilitate the evaluation of various drug concentrations (Khoo et al., 2016).

Despite considerable progress in the development of targeted therapies, very little improvement in patient outcomes has been achieved for many of the common cancers. Tumor heterogeneity, evolution, and acquired drug resistance are some of the responsible factors which need to be taken into consideration for the development of precision cancer medicine. However, the development of genotype-informed treatment strategies is highly reliant on robust drug screening systems. Cultures of immortalized cancer cells are unable to recapitulate the heterogeneity and dynamic molecular evolution of cancers (Praharaj et al., 2018). Mouse models, particularly patient-derived xenograft models, are not suitable for high-throughput drug screening. Ease of retrieving CTCs makes them a superior candidate for establishing personalized in vitro tumor models compared to tissue biopsies. Progress in ex vivo CTC culture methods may help in establishing more robust and personalized treatment response evaluation systems. However, the change in CTC physiology during such external culture 
environments in comparison to the bloodstream is still questionable and needs to be further investigated. This will then ensure an improved understanding of CTC and metastasis biology. However, to the best of our knowledge, so far, no methods have been established for culturing of patient-derived CTC-clusters. In order to gain an in depth knowledge of CTM biology, as well as realize their clinical potential to the full extent, there is a need to for the parallel development of platforms capable of expansion of patient-derived CTM in addition to just developing isolation platforms.

\section{Conclusion and Future Perspectives}

CTM as unique conglomerates of tumor and various non-tumor cells that are far more potent initiators of metastasis as compared to single CTCs may hold the key to thorough decipherment of metastatic cascade. Although higher propensity of CTM to distant colonization been known since mid- $20^{\text {th }}$ century, it is only due to technological advances during the past few years that a better understanding of molecular and phenotypic characteristics governing this phenomenon has been gained. However, many of the fundamental questions remain unanswered or inadequately explained. As such, it is not clear whether different tumor cells within CTM are equally metastable or what is the effect of size and number of cells in cluster on its metastatic potential (Krebs et al., 2014). Contribution of associated non-tumor cells to hematogenous survival and more efficient distant colonization compared to single CTCs, as well as mechanisms that enable collective migration are among the prominent outstanding questions in CTM biology (Aceto et al., 2015).

Scarcity of methods and devices that can efficiently identify, enumerate, and isolate CTM can be considered as the prominent reason for these gaps in our knowledge. In addition to the apparent bias of currently available platforms towards single CTCs, heterogeneity of biomarkers currently being used for capture or post-isolation/enrichment identification of CTM are the key technological constraints which warrant attention. Though recent discoveries have shown promise (Au et al., 2017; Sarioglu et al., 2015), it is still a long a way before these advances can be translated to routine clinical applications. Ex-vivo expansion of patientderived CTCs is an emerging avenue in cancer research. However, so far, no methods have been reported for specific culturing and expansion of CTM. Research in the coming years must focus on developing strategies for long-term culture of patient-derived CTM as such expansion platforms hold great translational promise. Finally, more research is needed to devise novel 
CTM targeting therapeutic agents as this strategy may prove to be an effective way of curtailing metastatic cancer spread.

\section{Acknowledgments:}

This work was supported by the NHMRC CDF (APP1088966) to M.J.A.S. 


\section{References:}

Aceto, N., Bardia, A., et al., 2014. Circulating tumor cell clusters are oligoclonal precursors of breast cancer metastasis. Cell 158(5), 1110-1122.

Aceto, N., Toner, M., et al., 2015. En Route to Metastasis: Circulating Tumor Cell Clusters and Epithelial-to-Mesenchymal Transition. Trends Cancer 1(1), 44-52.

Adams, A.A., Okagbare, P.I., et al., 2008. Highly efficient circulating tumor cell isolation from whole blood and label-free enumeration using polymer-based microfluidics with an integrated conductivity sensor. J. Am. Chem. Soc. 130(27), 8633-8641.

Adams, D.L., Zhu, P., et al., 2014. The systematic study of circulating tumor cell isolation using lithographic microfilters. RSC Advances 4(9), 4334-4342.

Al-Mehdi, A.B., Tozawa, K., et al., 2000. Intravascular origin of metastasis from the proliferation of endothelium-attached tumor cells: a new model for metastasis. Nat. Med. 6(1), 100-102.

Alix-Panabieres, C., Pantel, K., 2014. Challenges in circulating tumour cell research. Nat. Rev. Cancer 14(9), 623-631.

Alix-Panabieres, C., Schwarzenbach, H., et al., 2012. Circulating tumor cells and circulating tumor DNA. Annu. Rev. Med. 63, 199-215.

Allard, W.J., Matera, J., et al., 2004. Tumor cells circulate in the peripheral blood of all major carcinomas but not in healthy subjects or patients with nonmalignant diseases. Clin. Cancer Res. 10(20), 6897-6904.

Ameri, K., Luong, R., et al., 2010. Circulating tumour cells demonstrate an altered response to hypoxia and an aggressive phenotype. Br. J. Cancer 102, 561.

Ashworth, T.R., 1869. A case of cancer in which cells similar to those in the tumors were seen in the blood after death. Aust. Med. J. 14, 146-149.

Au, S.H., Edd, J., et al., 2017. Microfluidic Isolation of Circulating Tumor Cell Clusters by Size and Asymmetry. Sci. Rep. 7, 2433.

Au, S.H., Storey, B.D., et al., 2016. Clusters of circulating tumor cells traverse capillary-sized vessels. Proc. Natl. Acad. Sci. U. S. A. 113(18), 4947-4952.

Baas, T., 2013. CTCs gain character (ization). SciBX 6(17).

Bednarz, N., Eltze, E., et al., 2010. BRCA1 loss preexisting in small subpopulations of prostate cancer is associated with advanced disease and metastatic spread to lymph nodes and peripheral blood. Clin. Cancer Res. 16(13), 3340-3348. 
Bithi, S.S., Vanapalli, S.A., 2017. Microfluidic cell isolation technology for drug testing of single tumor cells and their clusters. Sci. Rep. 7, 41707.

Bobek, V., Kacprzak, G., et al., 2014a. Detection and Cultivation of Circulating Tumor Cells in Malignant Pleural Mesothelioma. Anticancer Res. 34(5), 2565-2569.

Bobek, V., Matkowski, R., et al., 2014b. Cultivation of circulating tumor cells in esophageal cancer. Folia Histochem. Cytobiol. 52(3), 171-177.

Brandt, B., Junker, R., et al., 1996. Isolation of prostate-derived single cells and cell clusters from human peripheral blood. Cancer Res. 56(20), 4556-4561.

Brandt, B., Roetger, A., et al., 1998. Isolation of blood-borne epithelium-derived c-erbB-2 oncoprotein-positive clustered cells from the peripheral blood of breast cancer patients. Int. J. Cancer 76(6), 824-828.

Calbo, J., van Montfort, E., et al., 2011. A functional role for tumor cell heterogeneity in a mouse model of small cell lung cancer. Cancer Cell 19(2), 244-256.

Cayrefourcq, L., Mazard, T., et al., 2015. Establishment and Characterization of a Cell Line from Human Circulating Colon Cancer Cells. Cancer Res. 75(5), 892-901.

Cegan, M., Kolostova, K., et al., 2014. In vitro culturing of viable circulating tumor cells of urinary bladder cancer. Int. J. Clin. Exp. Pathol. 7(10), 7164-7171.

Chaffer, C.L., Weinberg, R.A., 2011. A perspective on cancer cell metastasis. Science 331(6024), 1559-1564.

Chang, M.-C., Chang, Y.-T., et al., 2016. Clinical Significance of Circulating Tumor Microemboli as a Prognostic Marker in Patients with Pancreatic Ductal Adenocarcinoma. Clin. Chem. 62(3), 505-513.

Chen, J.Y., Tsai, W.S., et al., 2016. Sensitive and Specific Biomimetic Lipid Coated Microfluidics to Isolate Viable Circulating Tumor Cells and Microemboli for Cancer Detection. PLoS One 11(3), e0149633.

Cheng, S.-B., Xie, M., et al., 2017. Three-Dimensional Scaffold Chip with Thermosensitive Coating for Capture and Reversible Release of Individual and Cluster of Circulating Tumor Cells. Anal. Chem. 89(15), 7924-7932.

Cheng, S.B., Xie, M., et al., 2016. High-Efficiency Capture of Individual and Cluster of Circulating Tumor Cells by a Microchip Embedded with Three-Dimensional Poly(dimethylsiloxane) Scaffold. Anal. Chem. 88(13), 6773-6780.

Cheung, K.J., Gabrielson, E., et al., 2013. Collective invasion in breast cancer requires a conserved basal epithelial program. Cell 155(7), 1639-1651. 
Cheung, K.J., Padmanaban, V., et al., 2016. Polyclonal breast cancer metastases arise from collective dissemination of keratin 14-expressing tumor cell clusters. Proc. Natl. Acad. Sci. U. S. A. 113(7), E854-E863.

Cho, E.H., Wendel, M., et al., 2012. Characterization of circulating tumor cell aggregates identified in patients with epithelial tumors. Phys. Biol. 9(1), 016001.

Choi, J.W., Kim, J.K., et al., 2015. Urokinase exerts antimetastatic effects by dissociating clusters of circulating tumor cells. Cancer Res. 75(21), 4474-4482.

Choi, S., Ku, T., et al., 2011. Hydrophoretic high-throughput selection of platelets in physiological shear-stress range. Lab Chip 11(3), 413-418.

Cima, I., Kong, S.L., et al., 2016. Tumor-derived circulating endothelial cell clusters in colorectal cancer. Sci. Transl. Med. 8(345), 345ra389.

Cima, I., Wen Yee, C., et al., 2013. Label-free isolation of circulating tumor cells in microfluidic devices: Current research and perspectives. Biomicrofluidics 7(1), 011810.

Coman, D.R., de, L.R., et al., 1951. Studies on the mechanisms of metastasis; the distribution of tumors in various organs in relation to the distribution of arterial emboli. Cancer Res. 11(8), 648-651.

Cross, S.E., Jin, Y.S., et al., 2008. AFM-based analysis of human metastatic cancer cells. Nanotechnology 19(38), 384003.

Dasgupta, A., Lim, A.R., et al., 2017. Circulating and disseminated tumor cells: harbingers or initiators of metastasis? Mol. Oncol. 11(1), 40-61.

Desitter, I., Guerrouahen, B.S., et al., 2011. A new device for rapid isolation by size and characterization of rare circulating tumor cells. Anticancer Res. 31(2), 427-441.

Di Carlo, D., 2009. Inertial microfluidics. Lab Chip 9(21), 3038-3046.

Di Carlo, D., Irimia, D., et al., 2007. Continuous inertial focusing, ordering, and separation of particles in microchannels. Proc. Natl. Acad. Sci. U. S. A. 104(48), 18892-18897.

Dong, X., Guan, J., et al., 2010. Patient-derived first generation xenografts of non-small cell lung cancers: promising tools for predicting drug responses for personalized chemotherapy. Clin. Cancer Res. 16(5), 1442-1451.

Douma, S., Van Laar, T., et al., 2004. Suppression of anoikis and induction of metastasis by the neurotrophic receptor TrkB. Nature 430(7003), 1034-1039.

Duda, D.G., Duyverman, A.M., et al., 2010. Malignant cells facilitate lung metastasis by bringing their own soil. Proc. Natl. Acad. Sci. U. S. A. 107(50), 21677-21682.

Esmaeilsabzali, H., Beischlag, T.V., et al., 2013. Detection and isolation of circulating tumor cells: principles and methods. Biotechnol. Adv. 31(7), 1063-1084. 
Fabisiewicz, A., Grzybowska, E., 2017. CTC clusters in cancer progression and metastasis. Med. Oncol. 34(1), 12.

Fanelli, M.F., Oliveira, T.B., et al., 2017. Evaluation of incidence, significance, and prognostic role of circulating tumor microemboli and transforming growth factor- $\beta$ receptor $I$ in head and neck cancer. Head Neck 39(11), 2283-2292.

Fidler, I.J., 1973. The relationship of embolic homogeneity, number, size and viability to the incidence of experimental metastasis. Eur. J. Cancer 9(3), 223-227.

Fidler, I.J., 1974. Immune stimulation-inhibition of experimental cancer metastasis. Cancer Res. 34(3), 491-498.

Friedl, P., Wolf, K., 2009. Proteolytic interstitial cell migration: a five-step process. Cancer Metastasis Rev. 28(1-2), 129-135.

Friedlander, T.W., Ngo, V.T., et al., 2014. Detection and characterization of invasive circulating tumor cells derived from men with metastatic castration-resistant prostate cancer. Int. J. Cancer 134(10), 2284-2293.

Frisch, S.M., Screaton, R.A., 2001. Anoikis mechanisms. Curr. Opin. Cell Biol. 13(5), 555562.

Gao, D., Vela, I., et al., 2014. Organoid Cultures Derived from Patients with Advanced Prostate Cancer. Cell 159(1), 176-187.

Gao, W., Yuan, H., et al., 2016. Analysis of circulating tumor cells from lung cancer patients with multiple biomarkers using high-performance size-based microfluidic chip. Oncotarget 8(8), 12917-12928.

Ge, F., Zhang, H., et al., 2015. Enhanced detection and comprehensive in situ phenotypic characterization of circulating and disseminated heteroploid epithelial and glioma tumor cells. Oncotarget 6(29), 27049-27064.

Giuliano, M., Shaikh, A., et al., 2018. Perspective on Circulating Tumor Cell Clusters: Why It Takes a Village to Metastasize. Cancer Res.

Glinsky, V.V., Glinsky, G.V., et al., 2003. Intravascular metastatic cancer cell homotypic aggregation at the sites of primary attachment to the endothelium. Cancer Res. 63(13), 38053811 .

Hanahan, D., Weinberg, R., 2011. Hallmarks of cancer: the next generation. Cell 144(5), 646674.

Harouaka, R.A., Zhou, M.D., et al., 2014. Flexible micro spring array device for highthroughput enrichment of viable circulating tumor cells. Clin. Chem. 60(2), 323-333. 
Harper, K.L., Sosa, M.S., et al., 2016. Mechanism of early dissemination and metastasis in Her2+ mammary cancer. Nature 540(7634), 588-592.

Hayashi, M., Zhu, P., et al., 2017. Size-based detection of sarcoma circulating tumor cells and cell clusters. Oncotarget 8(45), 78965-78977.

Hejazian, M., Li, W., et al., 2015. Lab on a chip for continuous-flow magnetic cell separation. Lab Chip 15(4), 959-970.

Hong, B., Zu, Y., 2013. Detecting circulating tumor cells: current challenges and new trends. Theranostics 3(6), 377-394.

Hong, Y., Fang, F., et al., 2016. Circulating tumor cell clusters: What we know and what we expect (Review). Int. J. Oncol. 49(6), 2206-2216.

Hosokawa, M., Kenmotsu, H., et al., 2013. Size-based isolation of circulating tumor cells in lung cancer patients using a microcavity array system. PLoS One 8(6), e67466.

Hosseini, H., Obradovic, M.M., et al., 2016. Early dissemination seeds metastasis in breast cancer. Nature 540(7634), 552-558.

Hou, H.W., Warkiani, M.E., et al., 2013. Isolation and retrieval of circulating tumor cells using centrifugal forces. Sci. Rep. 3, 1259.

Hou, J.M., Krebs, M., et al., 2011. Circulating tumor cells as a window on metastasis biology in lung cancer. Am. J. Pathol. 178(3), 989-996.

Hou, J.M., Krebs, M.G., et al., 2012. Clinical significance and molecular characteristics of circulating tumor cells and circulating tumor microemboli in patients with small-cell lung cancer. J. Clin. Oncol. 30(5), 525-532.

Huang, L.R., Cox, E.C., et al., 2004. Continuous particle separation through deterministic lateral displacement. Science 304(5673), 987-990.

Huang, T., Jia, C.P., et al., 2014. Highly sensitive enumeration of circulating tumor cells in lung cancer patients using a size-based filtration microfluidic chip. Biosens. Bioelectron. 51, 213-218.

Hur, S.C., Henderson-MacLennan, N.K., et al., 2011. Deformability-based cell classification and enrichment using inertial microfluidics. Lab Chip 11(5), 912-920.

Jansson, S., Bendahl, P.O., et al., 2016. Prognostic impact of circulating tumor cell apoptosis and clusters in serial blood samples from patients with metastatic breast cancer in a prospective observational cohort. BMC Cancer 16(1), 433-447.

Jin, C., McFaul, S.M., et al., 2014. Technologies for label-free separation of circulating tumor cells: from historical foundations to recent developments. Lab Chip 14(1), 32-44. 
Joosse, S.A., Gorges, T.M., et al., 2015. Biology, detection, and clinical implications of circulating tumor cells. EMBO Mol. Med. 7(1), 1-11.

Kalluri, R., 2009. EMT: when epithelial cells decide to become mesenchymal-like cells. J. Clin. Invest. 119(6), 1417-1419.

Kang, J.H., Choi, S., et al., 2008. Isomagnetophoresis to discriminate subtle difference in magnetic susceptibility. J. Am. Chem. Soc. 130(2), 396-397.

Kang, J.H., Krause, S., et al., 2012. A combined micromagnetic-microfluidic device for rapid capture and culture of rare circulating tumor cells. Lab Chip 12(12), 2175-2181.

Kats-Ugurlu, G., Roodink, I., et al., 2009. Circulating tumour tissue fragments in patients with pulmonary metastasis of clear cell renal cell carcinoma. J. Pathol. 219(3), 287-293.

Khoja, L., Backen, A., et al., 2012. A pilot study to explore circulating tumour cells in pancreatic cancer as a novel biomarker. Br. J. Cancer 106(3), 508-516.

Khoo, B.L., Grenci, G., et al., 2016. Liquid biopsy and therapeutic response: Circulating tumor cell cultures for evaluation of anticancer treatment. Science Advances 2(7).

Khoo, B.L., Grenci, G., et al., 2017. Expansion of patient-derived circulating tumor cells from liquid biopsies using a CTC microfluidic culture device. Nat. Protoc. 13, 34.

Kim, T.H., Yoon, H.J., et al., 2014. Cascaded spiral microfluidic device for deterministic and high purity continuous separation of circulating tumor cells. Biomicrofluidics 8(6), 064117.

King, M.R., Phillips, K.G., et al., 2015. A physical sciences network characterization of circulating tumor cell aggregate transport. Am. J. Physiol. Cell Physiol. 308(10), C792-C802. Klein, C.A., 2009. Parallel progression of primary tumours and metastases. Nat. Rev. Cancer 9(4), 302-312.

Knisely, W.H., Mahaley, M.S., Jr., 1958. Relationship between size and distribution of spontaneous metastases and three sizes of intravenously injected particles of VX2 carcinoma. Cancer Res. 18(8 Part 1), 900-905.

Kopp, H.G., Placke, T., et al., 2009. Platelet-derived transforming growth factor-beta downregulates NKG2D thereby inhibiting natural killer cell antitumor reactivity. Cancer Res. 69(19), 7775-7783.

Krebs, M.G., Hou, J.M., et al., 2012. Analysis of circulating tumor cells in patients with nonsmall cell lung cancer using epithelial marker-dependent and -independent approaches. J. Thorac. Oncol. 7(2), 306-315.

Krebs, M.G., Metcalf, R.L., et al., 2014. Molecular analysis of circulating tumour cells-biology and biomarkers. Nat. Rev. Clin. Oncol. 11(3), 129-144. 
Kulasinghe, A., Tran, T.H., et al., 2017. Enrichment of circulating head and neck tumour cells using spiral microfluidic technology. Sci. Rep. 7, 42517.

Kuntaegowdanahalli, S.S., Bhagat, A.A.S., et al., 2009. Inertial microfluidics for continuous particle separation in spiral microchannels. Lab Chip 9(20), 2973-2980.

Kusters, B., Kats, G., et al., 2007. Micronodular transformation as a novel mechanism of VEGF-A-induced metastasis. Oncogene 26(39), 5808-5815.

Labelle, M., Begum, S., et al., 2011. Direct signaling between platelets and cancer cells induces an epithelial-mesenchymal-like transition and promotes metastasis. Cancer Cell 20(5), 576590.

Lai, C.H., Choon Lim, S., et al., 2017. Site-specific antibody modification and immobilization on a microfluidic chip to promote the capture of circulating tumor cells and microemboli. Chem. Commun. (Camb.) 53(29), 4152-4155.

Lambert, A.W., Pattabiraman, D.R., et al., 2017. Emerging Biological Principles of Metastasis. Cell 168(4), 670-691.

Langenbeck, B., 1841. On the development of cancer in the veins, and the transmission of cancer from man to the lower animals. Edin Med Surg J 55(147), 251-253.

Laubli, H., Stevenson, J.L., et al., 2006. L-selectin facilitation of metastasis involves temporal induction of Fut7-dependent ligands at sites of tumor cell arrest. Cancer Res. 66(3), 1536-1542. Lee, M., Kim, E.J., et al., 2017. Predictive value of circulating tumor cells (CTCs) captured by microfluidic device in patients with epithelial ovarian cancer. Gynecol. Oncol. 145(2), 361365.

Liang, S.B., Fu, L.W., 2017. Application of single-cell technology in cancer research. Biotechnol. Adv. 35(4), 443-449.

Lim, L.S., Hu, M., et al., 2012. Microsieve lab-chip device for rapid enumeration and fluorescence in situ hybridization of circulating tumor cells. Lab Chip 12(21), 4388-4396.

Liotta, L.A., Saidel, M.G., et al., 1976. The significance of hematogenous tumor cell clumps in the metastatic process. Cancer Res. 36(3), 889-894.

Lu, J., Fan, T., et al., 2010. Isolation of circulating epithelial and tumor progenitor cells with an invasive phenotype from breast cancer patients. Int. J. Cancer 126(3), 669-683.

Lu, Y.T., Zhao, L., et al., 2013. NanoVelcro Chip for CTC enumeration in prostate cancer patients. Methods 64(2), 144-152.

Maddipati, R., Stanger, B.Z., 2015. Pancreatic Cancer Metastases Harbor Evidence of Polyclonality. Cancer Discov. 5(10), 1086-1097. 
Maheswaran, S., Sequist, L.V., et al., 2008. Detection of mutations in EGFR in circulating lung-cancer cells. N. Engl. J. Med. 359(4), 366-377.

Markou, A., Strati, A., et al., 2011. Molecular characterization of circulating tumor cells in breast cancer by a liquid bead array hybridization assay. Clin. Chem. 57(3), 421-430.

Marrinucci, D., Bethel, K., et al., 2012. Fluid biopsy in patients with metastatic prostate, pancreatic and breast cancers. Phys. Biol. 9(1), 016003.

Massague, J., Obenauf, A.C., 2016. Metastatic colonization by circulating tumour cells. Nature 529(7586), 298-306.

McCarty, O.J., Mousa, S.A., et al., 2000. Immobilized platelets support human colon carcinoma cell tethering, rolling, and firm adhesion under dynamic flow conditions. Blood 96(5), 1789-1797.

McDonald, D.M., Baluk, P., 2002. Significance of blood vessel leakiness in cancer. Cancer Res. 62(18), 5381-5385.

Meng, S., Tripathy, D., et al., 2004. Circulating tumor cells in patients with breast cancer dormancy. Clin. Cancer Res. 10(24), 8152-8162.

Miyamoto, D.T., Lee, R.J., et al., 2012. Androgen receptor signaling in circulating tumor cells as a marker of hormonally responsive prostate cancer. Cancer Discov. 2(11), 995-1003.

Molnar, B., Ladanyi, A., et al., 2001. Circulating tumor cell clusters in the peripheral blood of colorectal cancer patients. Clin. Cancer Res. 7(12), 4080-4085.

Mu, Z., Wang, C., et al., 2015. Prospective assessment of the prognostic value of circulating tumor cells and their clusters in patients with advanced-stage breast cancer. Breast Cancer Res. Treat. 154(3), 563-571.

Murlidhar, V., Reddy, R.M., et al., 2017. Poor Prognosis Indicated by Venous Circulating Tumor Cell Clusters in Early-Stage Lung Cancers. Cancer Res. 77(18), 5194-5206.

Murlidhar, V., Zeinali, M., et al., 2014. A Radial Flow Microfluidic Device for Ultra-HighThroughput Affinity-Based Isolation of Circulating Tumor Cells. Small 10(23), 4895-4904.

Nagrath, S., Sequist, L.V., et al., 2007. Isolation of rare circulating tumour cells in cancer patients by microchip technology. Nature 450(7173), 1235-1239.

Nakano, A., Harada, T., et al., 1990. Expression of leukocyte common antigen (CD45) on various human leukemia/lymphoma cell lines. Acta Pathol. Jpn. 40(2), 107-115.

Neal, J.T., Kuo, C.J., 2016. Organoids as Models for Neoplastic Transformation. Annual Review of Pathology: Mechanisms of Disease 11(1), 199-220.

Nowell, P.C., 1976. The clonal evolution of tumor cell populations. Science 194(4260), 23-28. 
Ozkumur, E., Shah, A.M., et al., 2013. Inertial focusing for tumor antigen-dependent and independent sorting of rare circulating tumor cells. Sci. Transl. Med. 5(179), 179ra147.

Pantel, K., Deneve, E., et al., 2012. Circulating epithelial cells in patients with benign colon diseases. Clin. Chem. 58(5), 936-940.

Pantel, K., Speicher, M.R., 2016. The biology of circulating tumor cells. Oncogene 35(10), 1216-1224.

Paoletti, C., Li, Y., et al., 2015. Significance of Circulating Tumor Cells in Metastatic TripleNegative Breast Cancer Patients within a Randomized, Phase II Trial: TBCRC 019. Clin. Cancer Res. 21(12), 2771-2779.

Paoli, P., Giannoni, E., et al., 2013. Anoikis molecular pathways and its role in cancer progression. Biochim. Biophys. Acta 1833(12), 3481-3498.

Peeters, D.J., Brouwer, A., et al., 2015. Circulating tumour cells and lung microvascular tumour cell retention in patients with metastatic breast and cervical cancer. Cancer Lett. 356(2 Pt B), 872-879.

Phillips, K.G., Lee, A.M., et al., 2015. The thrombotic potential of circulating tumor microemboli: computational modeling of circulating tumor cell-induced coagulation. Am. J. Physiol. Cell Physiol. 308(3), C229-C236.

Praharaj, P.P., Bhutia, S.K., et al., 2018. Circulating tumor cell-derived organoids: Current challenges and promises in medical research and precision medicine. Biochim. Biophys. Acta. Proserpio, V., Lonnberg, T., 2016. Single-cell technologies are revolutionizing the approach to rare cells. Immunol. Cell Biol. 94(3), 225-229.

Reategui, E., Aceto, N., et al., 2015. Tunable nanostructured coating for the capture and selective release of viable circulating tumor cells. Adv. Mater. 27(9), 1593-1599.

Récamier, J.C., 1829. Recherches sur le traitement du cancer sur la compression methodique simple ou combinee et sur l'histoire generale de la meme maladie, 2nd ed. Gabon, Paris.

Reddy, R.M., Murlidhar, V., et al., 2016. Pulmonary venous blood sampling significantly increases the yield of circulating tumor cells in early-stage lung cancer. J. Thorac. Cardiovasc. Surg. 151(3), 852-857.

Rhim, A.D., Mirek, E.T., et al., 2012. EMT and dissemination precede pancreatic tumor formation. Cell 148(1-2), 349-361.

Riethdorf, S., Muller, V., et al., 2010. Detection and HER2 expression of circulating tumor cells: prospective monitoring in breast cancer patients treated in the neoadjuvant GeparQuattro trial. Clin. Cancer Res. 16(9), 2634-2645. 
Russom, A., Gupta, A.K., et al., 2009. Differential inertial focusing of particles in curved lowaspect-ratio microchannels. New J Phys 11, 075025.

Sanger, N., Effenberger, K.E., et al., 2011. Disseminated tumor cells in the bone marrow of patients with ductal carcinoma in situ. Int. J. Cancer 129(10), 2522-2526.

Sarioglu, A.F., Aceto, N., et al., 2015. A microfluidic device for label-free, physical capture of circulating tumor cell clusters. Nat. Methods 12(7), 685-691.

Sato, T., Stange, D.E., et al., 2011. Long-term expansion of epithelial organoids from human colon, adenoma, adenocarcinoma, and Barrett's epithelium. Gastroenterology 141(5), 17621772 .

Schiro, P.G., Zhao, M., et al., 2012. Sensitive and high-throughput isolation of rare cells from peripheral blood with ensemble-decision aliquot ranking. Angew. Chem. Int. Ed. Engl. 51(19), $4618-4622$.

Seal, S.H., 1959. Silicone flotation: a simple quantitative method for the isolation of freefloating cancer cells from the blood. Cancer 12(3), 590-595.

Segre, G., Silberberg, A., 1962a. Behaviour of macroscopic rigid spheres in Poiseuille flow Part 1. Determination of local concentration by statistical analysis of particle passages through crossed light beams. J. Fluid Mech. 14(1), 115-135.

Segre, G., Silberberg, A., 1962b. Behaviour of macroscopic rigid spheres in Poiseuille flow Part 2. Experimental results and interpretation. J. Fluid Mech. 14(su1), 136-157.

Sequist, L.V., Nagrath, S., et al., 2009. The CTC-chip: an exciting new tool to detect circulating tumor cells in lung cancer patients. J. Thorac. Oncol. 4(3), 281-283.

Sheng, W., Ogunwobi, O.O., et al., 2014. Capture, release and culture of circulating tumor cells from pancreatic cancer patients using an enhanced mixing chip. Lab Chip 14(1), 89-98.

Smirnov, D.A., Zweitzig, D.R., et al., 2005. Global gene expression profiling of circulating tumor cells. Cancer Res. 65(12), 4993-4997.

Sollier, E., Go, D.E., et al., 2014. Size-selective collection of circulating tumor cells using Vortex technology. Lab Chip 14(1), 63-77.

Stott, S.L., Hsu, C.H., et al., 2010a. Isolation of circulating tumor cells using a microvortexgenerating herringbone-chip. Proc. Natl. Acad. Sci. U. S. A. 107(43), 18392-18397.

Stott, S.L., Lee, R.J., et al., 2010b. Isolation and characterization of circulating tumor cells from patients with localized and metastatic prostate cancer. Sci. Transl. Med. 2(25), 25ra23.

Stroock, A.D., Dertinger, S.K., et al., 2002. Chaotic mixer for microchannels. Science 295(5555), 647-651. 
Sugino, T., Yamaguchi, T., et al., 2004. Morphological evidence for an invasion-independent metastasis pathway exists in multiple human cancers. BMC Med. 2, 9-16.

Talmadge, J.E., Fidler, I.J., 2010. AACR centennial series: the biology of cancer metastasis: historical perspective. Cancer Res. 70(14), 5649-5669.

Tam, W.L., Weinberg, R.A., 2013. The epigenetics of epithelial-mesenchymal plasticity in cancer. Nat. Med. 19(11), 1438-1449.

Tarin, D., Thompson, E.W., et al., 2005. The fallacy of epithelial mesenchymal transition in neoplasia. Cancer Res. 65(14), 5996-6001.

Thiele, J.A., Bethel, K., et al., 2017. Circulating Tumor Cells: Fluid Surrogates of Solid Tumors. Annu. Rev. Pathol. 12, 419-447.

Thiersch, K., 1865. Der Epithelial krebs, namentlich der Hand. Engelmann, Leipzig.

Thompson, S.C., 1974. The colony forming efficiency of single cells and cell aggregates from a spontaneous mouse mammary tumour using the lung colony assay. Br. J. Cancer 30(4), 332336.

Tomlinson, J.S., Alpaugh, M.L., et al., 2001. An intact overexpressed E-cadherin/alpha,betacatenin axis characterizes the lymphovascular emboli of inflammatory breast carcinoma. Cancer Res. 61(13), 5231-5241.

Tsuji, T., Ibaragi, S., et al., 2008. Epithelial-mesenchymal transition induced by growth suppressor p12CDK2-AP1 promotes tumor cell local invasion but suppresses distant colony growth. Cancer Res. 68(24), 10377-10386.

Upreti, M., Jamshidi-Parsian, A., et al., 2011. Tumor-Endothelial Cell Three-dimensional Spheroids: New Aspects to Enhance Radiation and Drug Therapeutics. Transl. Oncol. 4(6), 365-376.

Virchow, R., 1858. Cellular pathologie. Nutr. Rev., 23-25.

Vona, G., Estepa, L., et al., 2004. Impact of cytomorphological detection of circulating tumor cells in patients with liver cancer. Hepatology 39(3), 792-797.

Vona, G., Sabile, A., et al., 2000. Isolation by size of epithelial tumor cells : a new method for the immunomorphological and molecular characterization of circulatingtumor cells. Am. J. Pathol. 156(1), 57-63.

Wang, H., Riha, G.M., et al., 2005. Shear stress induces endothelial differentiation from a murine embryonic mesenchymal progenitor cell line. Arterioscler. Thromb. Vasc. Biol. 25(9), 1817-1823. 
Wang, S., Thomas, A., et al., 2016. Highly efficient and selective isolation of rare tumor cells using a microfluidic chip with wavy-herringbone micro-patterned surfaces. Analyst 141(7), 2228-2237.

Wang, Y., Navin, N.E., 2015. Advances and applications of single-cell sequencing technologies. Mol. Cell 58(4), 598-609.

Wang, Z.P., Eisenberger, M.A., et al., 2000. Identification and characterization of circulating prostate carcinoma cells. Cancer 88(12), 2787-2795.

Warkiani, M.E., Khoo, B.L., et al., 2016. Ultra-fast, label-free isolation of circulating tumor cells from blood using spiral microfluidics. Nat. Protoc. 11(1), 134-148.

Watanabe, S., 1954. The metastasizability of tumor cells. Cancer 7(2), 215-223.

Weeber, F., van de Wetering, M., et al., 2015. Preserved genetic diversity in organoids cultured from biopsies of human colorectal cancer metastases. Proceedings of the National Academy of Sciences 112(43), 13308-13311.

Wels, J., Kaplan, R.N., et al., 2008. Migratory neighbors and distant invaders: tumor-associated niche cells. Genes Dev. 22(5), 559-574.

Xavier, M., Oreffo, R.O., et al., 2016. Skeletal stem cell isolation: A review on the state-ofthe-art microfluidic label-free sorting techniques. Biotechnol. Adv. 34(5), 908-923.

Xu, Y., Qin, T., et al., 2017. Detection of Circulating Tumor Cells Using Negative Enrichment Immunofluorescence and an In Situ Hybridization System in Pancreatic Cancer. Int. J. Mol. Sci. 18(4), 622-639.

Yap, B., Kamm, R.D., 2005. Cytoskeletal remodeling and cellular activation during deformation of neutrophils into narrow channels. J Appl Physiol (1985) 99(6), 2323-2330.

Yokobori, T., Iinuma, H., et al., 2013. Plastin3 is a novel marker for circulating tumor cells undergoing the epithelial-mesenchymal transition and is associated with colorectal cancer prognosis. Cancer Res. 73(7), 2059-2069.

Yu, M., Bardia, A., et al., 2014. Ex vivo culture of circulating breast tumor cells for individualized testing of drug susceptibility. Science 345(6193), 216-220.

Yu, M., Bardia, A., et al., 2013. Circulating breast tumor cells exhibit dynamic changes in epithelial and mesenchymal composition. Science 339(6119), 580-584.

Yu, M., Stott, S., et al., 2011. Circulating tumor cells: approaches to isolation and characterization. J. Cell Biol. 192(3), 373-382.

Yu, M., Ting, D.T., et al., 2012. RNA sequencing of pancreatic circulating tumour cells implicates WNT signalling in metastasis. Nature 487(7408), 510-513.

Zeidman, I., 1957. Metastasis: a review of recent advances. Cancer Res. 17(3), 157-162. 
Zeidman, I., Buss, J.M., 1952. Transpulmonary passage of tumor cell emboli. Cancer Res. 12(10), 731-733.

Zhang, D., Zhao, L., et al., 2017. Circulating tumor microemboli (CTM) and vimentin+ circulating tumor cells (CTCs) detected by a size-based platform predict worse prognosis in advanced colorectal cancer patients during chemotherapy. Cancer Cell Int. 17, 6.

Zhang, L., Ridgway, L.D., et al., 2013. The Identification and Characterization of Breast Cancer CTCs Competent for Brain Metastasis. Sci. Transl. Med. 5(180), 180ra148-180ra148. Zhang, Z., Shiratsuchi, H., et al., 2014. Expansion of CTCs from early stage lung cancer patients using a microfluidic co-culture model. Oncotarget 5(23), 12383-12397.

Zhao, M., Nelson, W.C., et al., 2013. New generation of ensemble-decision aliquot ranking based on simplified microfluidic components for large-capacity trapping of circulating tumor cells. Anal. Chem. 85(20), 9671-9677.

Zheng, S., Lin, H.K., et al., 2011. 3D microfilter device for viable circulating tumor cell (CTC) enrichment from blood. Biomed. Microdevices 13(1), 203-213.

Zheng, X., Carstens, J.L., et al., 2015. Epithelial-to-mesenchymal transition is dispensable for metastasis but induces chemoresistance in pancreatic cancer. Nature 527(7579), 525-530.

Zheng, X., Fan, L., et al., 2017. Detection of Circulating Tumor Cells and Circulating Tumor Microemboli in Gastric Cancer. Transl. Oncol. 10(3), 431-441. 
Table 1: Macroscale Approaches for CTM Isolation

\begin{tabular}{|c|c|c|c|}
\hline Technology & $\begin{array}{l}\text { Device Architecture and Capture } \\
\text { Principle }\end{array}$ & $\begin{array}{l}\text { Key Features, Clinical } \\
\text { Applications, and Discoveries }\end{array}$ & References \\
\hline \multirow[t]{2}{*}{$\begin{array}{l}\text { Buoyant Density Gradient } \\
\text { and Immunomagnetic Cell } \\
\text { Separation }\end{array}$} & $\begin{array}{l}\text { Density gradient separation of } \\
\text { CTCs/CTM } \\
\text { Specific isolation by anti-CK coated } \\
\text { superparamagnetic microbeads } \\
\text { (or anti-CD45 based negative } \\
\text { immunomagnetic enrichment) }\end{array}$ & $\begin{array}{l}\text { Number of Double + (anti-CK/e- } \\
\text { erbB-2) CTM directly correlated to } \\
\text { disease stage in BRCA patients } \\
\text { CTM identified in more patients } \\
\text { compared to single cells } \\
\text { BRCA derived double + CTM show } \\
\text { high potential for locomotion }\end{array}$ & $\begin{array}{l}\text { (Brandt et al., 1996; } \\
\text { Brandt et al., 1998) }\end{array}$ \\
\hline & $\begin{array}{l}\text { Density gradient separation followed } \\
\text { by anti-CD } 45 \text { based negative } \\
\text { immunomagnetic enrichment }\end{array}$ & $\begin{array}{l}\text { CTM made up of } 3-100 \text { cells } \\
\text { identified and entirely composed of } \\
\text { growing/ living cells (significant } \\
\text { terminal single CTC population) }\end{array}$ & (Wang et al., 2000) \\
\hline $\begin{array}{l}\text { Immunomagnetic cell } \\
\text { separation }\end{array}$ & $\begin{array}{l}\text { Anti-CK } 7 / 8 \text { based immunomagnetic } \\
\text { cell separation followed by } \\
\text { cytocentrifugation }\end{array}$ & $\begin{array}{l}\text { CTM found to be more frequent } \\
\text { compared to single CTC events in } \\
\text { almost all of the CRC patients }\end{array}$ & (Molnar et al., 2001) \\
\hline \multirow[t]{2}{*}{ ISET® } & $\begin{array}{l}\text { Filtration through polycarbonate } \\
\text { membrane containing } 8 \mu \mathrm{m} \text { track- } \\
\text { etched cylindrical pores }\end{array}$ & $\begin{array}{l}\text { Intra-patient heterogenous EpCAM } \\
\text { expression in CTM } \\
\text { E-cadherin: expression and sub- } \\
\text { cellular localization highly } \\
\text { heterogenous (both inter- \& intra- } \\
\text { patient), and loss of plasma } \\
\text { membrane localization, } \\
\text { Heterogenous expression of CKs } \\
\text { High (but heterogenous) expression } \\
\text { of EMT markers; vimentin and } \\
\text { neural cadherin } \\
\text { Vimentin and E-cadherin } \\
\text { expression mutually exclusive }\end{array}$ & (Hou et al., 2011) \\
\hline & & $\begin{array}{l}\text { Absence of proliferating }(\mathrm{Ki} 67+) \\
\text { cells within CTM } \\
\text { CTM size: } 20-130 \mu \mathrm{m}\end{array}$ & (Hou et al., 2012) \\
\hline
\end{tabular}




\begin{tabular}{|c|c|c|c|}
\hline & & $\begin{array}{l}\text { Absence of EpCAM expression } \\
\text { Positive for CK \& EGFR }\end{array}$ & \\
\hline & & $\begin{array}{l}\text { CK+ and CK- cells coexist in CTM } \\
\text { EpCAM negative CTM also } \\
\text { detected } \\
\text { Heterogenous expression of EMT } \\
\text { markers E-cadherin and Vimentin } \\
\text { within CTM }\end{array}$ & (Khoja et al., 2012) \\
\hline \multirow[t]{2}{*}{ CellSearch ${ }^{\circledR}$} & Anti-EpCAM conjugated ferrofluids & $\begin{array}{l}\text { Cluster, ring, and elongated strand } \\
\text { shaped CTM identified } \\
\text { Absence of apoptotic cells within } \\
\text { CTM } \\
\text { Inter-patient \& intra-CTM } \\
\text { heterogeneity in CK expression }\end{array}$ & (Hou et al., 2011) \\
\hline & & $\begin{array}{l}\text { Absence of apoptotic cells within } \\
\text { CTM } \\
\text { Baseline CTM number correlated } \\
\text { with stage, lactate dehydrogenase, } \\
\text { presence of liver metastases, \& } \\
\text { number of metastasis sites, shorter } \\
\text { PFS and OS }\end{array}$ & (Hou et al., 2012) \\
\hline CAM Assay & $\begin{array}{l}\text { Ficoll density gradient centrifugation } \\
\text { followed by adhesion to CAM coated } \\
\text { wells of chamber slides }\end{array}$ & $\begin{array}{l}\text { In castration-resistant PCA patients, } \\
\text { CTM number did not correlate with } \\
\text { the number of single CTCs } / \mathrm{ml}\end{array}$ & (Friedlander et al., 2014) \\
\hline FMSA & $\begin{array}{l}\text { Size based filtration through micro } \\
\text { spring array }\end{array}$ & $\begin{array}{l}\text { Around } 35 \% \text { of all CTCs occurred } \\
\text { in clusters } \\
\text { Can process } 7.5 \mathrm{ml} \text { blood in } 10 \mathrm{~min} \\
>80 \% \text { viability of recovered cells }\end{array}$ & (Harouaka et al., 2014) \\
\hline $\begin{array}{l}\text { Subtraction/Negative } \\
\text { Enrichment-iFISH }\end{array}$ & $\begin{array}{l}\text { RBC depletion by centrifugation and } \\
\text { cell separation matrix. } \\
\text { Immunomagnetic WBCs depletion by } \\
\text { cocktail of multiple anti-leukocyte } \\
\text { antibodies }\end{array}$ & $\begin{array}{l}\text { In human cancer xenograft mouse } \\
\text { model: } \\
\text { Heterogenous CK18 expression } \\
\text { Sizes of cells within CTM similar to } \\
\text { those of WBCs }\end{array}$ & (Ge et al., 2015) \\
\hline
\end{tabular}




\begin{tabular}{l|ll}
\cline { 2 - 4 } & & $\begin{array}{l}\text { CTM detected only in stage IV } \\
\text { metastatic PCA patients } \\
\text { CTM detection significantly } \\
\text { correlated with reduced survival } \\
\text { and resistance to therapy }\end{array}$ \\
\hline CellSieve $^{\mathbf{T M}}$ & $\begin{array}{l}\text { Multiple microfilters each comprised } \\
\text { of an array of up to } \sim 160,000 \text { pores 5- } \\
9 \mu \mathrm{m} \text { in diameter }\end{array}$ & $\begin{array}{l}\text { CTM detected for the first time in } \\
\text { sarcoma patients }\end{array}$ \\
\hline
\end{tabular}

Abbreviations:

BRCA: Breast Cancer, CRC: Colorectal Cancer, CK: Cytokeratin, EGFR: Epithelial Growth Factor Receptor, PFS: Progression free survival, OS: Overall survival 
Table 2: Enrichment Free CTM Detection

\begin{tabular}{|c|c|c|c|}
\hline Technology & $\begin{array}{l}\text { Device Architecture and Capture } \\
\text { Principle }\end{array}$ & $\begin{array}{l}\text { Key Features, Clinical } \\
\text { Applications, and Discoveries }\end{array}$ & References \\
\hline Epic Platform & $\begin{array}{l}\mathrm{RBC} \text { lysis using } \mathrm{NH}_{4} \mathrm{Cl} \text { solution } \\
\text { Anti-CK, -CD45, -DAPI } \\
\text { immunofluorescent staining and high } \\
\text { speed automated microscopy }\end{array}$ & $\begin{array}{l}\text { High specificity (CTM detected in } \\
93 \% \text { of CTC+ stage IV PCA } \\
\text { patients but } 0 \% \text { healthy controls) } \\
\text { Cells in CTM smaller than singlet } \\
\text { CTCs, similar in size and length to } \\
\text { WBCs } \\
\text { CTM may be homotypic or } \\
\text { heterotypic (CTCs + leukocytes \& } \\
\text { platelets) }\end{array}$ & (Cho et al., 2012) \\
\hline $\begin{array}{l}\text { Ensemble-Decision } \\
\text { Aliquot Ranking (eDAR) }\end{array}$ & $\begin{array}{l}\text { Fluorescent anti-EpCAM (and/or- } \\
\text { HER2) labeling, laser illumination } \\
\text { and APD detection } \\
\text { Isolation of CTCs/CTM for further } \\
\text { analysis through (i) track etched } \\
\text { polycarbonate membrane filtration, or } \\
\text { (ii) Microfabricated slits }\end{array}$ & $\begin{array}{l}\text { Many CTM with low EpCAM } \\
\text { expression } \\
\text { Throughput: } 1 \mathrm{ml} \text { blood/12.5 min }\end{array}$ & $\begin{array}{l}\text { (Schiro et al., 2012; Zhao } \\
\text { et al., 2013) }\end{array}$ \\
\hline
\end{tabular}

Abbreviations: PCA: Prostate Cancer 
Table 3: Performance Comparison of Microfluidic CTM Enrichment Technologies

\begin{tabular}{|c|c|c|c|c|c|c|}
\hline Technology & Flow Rate & $\begin{array}{l}\text { Sample Volume } \\
\text { (Preprocessing) }\end{array}$ & Capture Efficiency & $\begin{array}{l}\text { Retrieval } \\
\text { Method }\end{array}$ & $\begin{array}{l}\text { Viability } \\
\text { (CTM } \\
\text { Integrity) }\end{array}$ & Purity \\
\hline CTC-Chip & $1 \mathrm{~mL} / \mathrm{hr}$ & $\sim 1-5 \mathrm{~mL}$ & $65 \% *$ & ND & $98.5 \pm 2.3 \%$ & $49-67 \%$ \\
\hline Herringbone-Chip & $\begin{array}{l}1.5-2.5 \\
\mathrm{~mL} / \mathrm{hr}\end{array}$ & $4 \mathrm{~mL}$ & $91.8 \pm 5.2 \% *$ & ND & $95 \pm 0.6 \%$ & $14 \%$ \\
\hline CTC-iChip & $8.4 \mathrm{~mL} / \mathrm{hr}$ & $2.6-9.1 \mathrm{~mL}$ & $\begin{array}{l}77.8 \pm 7.8 \% \text { to } \\
98.6 \pm 4.3 \% *\end{array}$ & Not required & ND & $\begin{array}{l}\text { Up to } 10^{\wedge} 4 \\
\text { WBC } \\
\text { depletion }\end{array}$ \\
\hline OncoBean Chip & $10 \mathrm{~mL} / \mathrm{hr}$ & $2-4.3 \mathrm{~mL}$ & $>80 \% *$ & ND & $\begin{array}{l}92.91 \pm \\
1.63 \%\end{array}$ & $\begin{array}{l}390-740 \\
\mathrm{WBCs} / \mathrm{mL}\end{array}$ \\
\hline 3D Scaffold Chip & $100 \mu \mathrm{L} / \mathrm{min}$ & $1 \mathrm{~mL}$ & $>90 \% *$ & $\begin{array}{l}37{ }^{\circ} \mathrm{C} \text { melting } \\
\text { of Gelatin } \\
\text { hydrogel } \\
\end{array}$ & $>90 \%{ }^{\delta}$ & ND \\
\hline CMx Platform & $1.5 \mathrm{~mL} / \mathrm{hr}$ & $2 \mathrm{~mL}$ & $93.7 \pm 8.9 \% *$ & Air Foam & $86 \% *$ & $\begin{array}{l}\text { Up to } 10^{\wedge} 4 \\
\text { WBC } \\
\text { depletion }\end{array}$ \\
\hline Microcavity Array & $200 \mu \mathrm{L} / \mathrm{min}$ & $4 \mathrm{~mL}$ & $68-100 \% *$ & N/A & Most & ND \\
\hline Spiral Chip & $3 \mathrm{~mL} / \mathrm{hr}$ & $\begin{array}{l}\text { 3-6 mL (1:2 } \\
\text { dilution) }\end{array}$ & $>85 \% *$ & Not required & $>98 \%$ & $\begin{array}{l}\text { Up to } 10^{\wedge} 4 \\
\text { WBC } \\
\text { depletion }\end{array}$ \\
\hline $\begin{array}{l}\text { Multiplex Spiral } \\
\text { Chip }\end{array}$ & $\begin{array}{l}7.5 \mathrm{~mL} / \\
12.5 \mathrm{~min}\end{array}$ & $\begin{array}{l}7.5 \mathrm{~mL} \text { of lysed } \\
\text { blood (RBC } \\
\text { lysis, } \\
\text { resuspension of } \\
\text { pellet in saline } \\
\text { to } 0.5 \times \text { of } \\
\text { original whole } \\
\text { blood volume) }\end{array}$ & $80.3 \pm 7.9 \% *$ & Not required & $87.5 \%$ & $\begin{array}{l}\text { Up to } 10^{\wedge} 4 \\
\text { WBC } \\
\text { depletion }\end{array}$ \\
\hline Vortex Chip & $4 \mathrm{~mL} / \mathrm{min}$ & $\begin{array}{l}7.5 \mathrm{~mL}(10 \mathrm{X} \\
\text { dilution) }\end{array}$ & $7-20 \% *$ & Not required & $\sim 90 \%$ & $57-95 \%$ \\
\hline
\end{tabular}




\begin{tabular}{|c|c|c|c|c|c|c|}
\hline $\begin{array}{l}\text { Microfluidic Chip } \\
\text { Tandem Triangular } \\
\text { Pillar and Filter } \\
\text { Channel Arrays }\end{array}$ & $15 \mathrm{~mL} / \mathrm{hr}$ & $\begin{array}{l}2 \mathrm{~mL}(\mathrm{RBC} \\
\text { lysis } \\
\text { resuspension of } \\
\text { pellet in PBS) }\end{array}$ & $>94 \% *$ & Not required & ND & ND \\
\hline Cluster Chip & $2.5 \mathrm{~mL} / \mathrm{hr}$ & $1-10 \mathrm{~mL}$ & $\begin{array}{l}41 \%(2 \text { cell CTM }) \\
99 \%(\geq 4 \text { cell CTM })\end{array}$ & $\begin{array}{l}250 \mathrm{~mL} / \mathrm{hr} \\
\text { Reverse flow } \\
\text { at, } 4{ }^{\circ} \mathrm{C}\end{array}$ & ND & ND \\
\hline $\begin{array}{l}\text { DLD Based 2-stage } \\
\text { Continuous Flow } \\
\text { Device }\end{array}$ & $0.5 \mathrm{~mL} / \mathrm{hr}$ & N/A & $\begin{array}{l}98.7 \pm 2.4 \% \text { (large } \\
\text { CTM) } \\
65.5 \pm 6.5 \% \text { (small } \\
\text { CTM) }\end{array}$ & No required & $\begin{array}{l}91.7 \pm 2.5 \% \\
(\sim 90 \%)\end{array}$ & ND \\
\hline
\end{tabular}

*Capture efficiency determined for single CTCs

¿Performance characteristics defined by later adaptation of original device (Cheng et al., 2017)

ND: Not determined 
Table 4: Microfluidic Technologies for CTM Enrichment

\begin{tabular}{|c|c|c|c|c|}
\hline Technology & $\begin{array}{l}\text { Device Architecture and } \\
\text { Capture Principle }\end{array}$ & Salient Features & $\begin{array}{l}\text { Key Clinical Applications } \\
\text { and Discoveries }\end{array}$ & References \\
\hline \multicolumn{5}{|c|}{ Marker Dependent Methods } \\
\hline CTC-Chip & $\begin{array}{l}\text { Array of anti-EpCAM } \\
\text { functionalized microposts }\end{array}$ & & $\begin{array}{l}\text { Identified CTM in lung } \\
\text { cancer patients }\end{array}$ & (Reddy et al., 2016) \\
\hline \multirow[t]{4}{*}{$\begin{array}{l}\text { Herringbone-Chip } \\
\text { ( }{ }^{\mathrm{HB}} \text { CTC-Chip) }\end{array}$} & $\begin{array}{l}\text { Anti-EpCAM functionalized } \\
\text { microchannel walls with } \\
\text { herringbone shaped grooves }\end{array}$ & $\begin{array}{l}\text { Enhanced mixing due to } \\
\text { microvortices. } \\
\text { Low shear design }\end{array}$ & $\begin{array}{l}\text { CTM not a result of in- } \\
\text { device CTC aggregation }\end{array}$ & (Stott et al., 2010) \\
\hline & $\begin{array}{l}\text { Microchannel walls } \\
\text { functionalized with Anti - } \\
\text { EpCAM, -EGFR, and - } \\
\text { HER2 }\end{array}$ & & $\begin{array}{l}\text { CTM strongly positive for } \\
\text { mesenchymal markers. } \\
\text { Most EMT transcriptional } \\
\text { regulators not detected in } \\
\text { the mesenchymal CTM } \\
\text { Evidence for in-circulation } \\
\text { EMT induction in CTM } \\
\text { mediated by TGF- } \beta \\
\text { released from CTM } \\
\text { associated platelets } \\
\text { In BRCA patient CTM } \\
\text { appearance correlated with } \\
\text { increased mesenchymal } \\
\text { CTCs }\end{array}$ & (Yu et al., 2013) \\
\hline & & & $\begin{array}{l}\text { CTM are clusters of } \\
\text { neighboring cells in } \\
\text { primary tumor } \\
\text { CTM hold up to } \sim 50 \mathrm{x} \text { more } \\
\text { metastatic potential } \\
\text { compared to singlet CTCs, }\end{array}$ & (Aceto et al., 2014) \\
\hline & $\begin{array}{l}\text { Nanocoating with } \\
\text { biotinylated-gelatin } \\
\text { Streptavidin-coated } \\
\end{array}$ & $\begin{array}{l}\text { Up to 5-fold increased } \\
\text { capture efficiency of low } \\
\text { EpCAM expressing cells }\end{array}$ & $\begin{array}{l}\text { Identified CTM in } 37.5 \% \\
\text { breast and } 25 \% \text { lung cancer } \\
\text { subjects }\end{array}$ & (Reategui et al., 2015) \\
\hline
\end{tabular}




\begin{tabular}{|c|c|c|c|c|}
\hline & $\begin{array}{l}\text { polystyrene nanoparticles } \\
\text { incorporated onto the top } \\
\text { surface of nanocoating }\end{array}$ & $\begin{array}{l}\text { Easy retrieval of viable } \\
\text { CTCs/CTM by hydrogel } \\
\text { melting at } 37 \mathrm{C}\end{array}$ & & \\
\hline \multirow[t]{2}{*}{ CTC-iChip } & $\begin{array}{l}\text { (i) Debulking by } \\
\text { deterministic lateral } \\
\text { displacement } \\
\text { (ii) Inertial focusing } \\
\text { (iii) Immunomagnetic } \\
\text { separation } \\
\text { (anti-EpCAM or anti-CD45) }\end{array}$ & $\begin{array}{l}\text { Capability to isolate } \\
\text { cells/clusters in suspension. } \\
\text { Positive (EpCAM) and } \\
\text { negative (CD45) selection } \\
\text { enables capture of broad } \\
\text { range of CTC/CTM } \\
\text { phenotypes }\end{array}$ & $\begin{array}{l}\text { CTM of 2-6 cells identified } \\
\text { in BRCA \& PCA }\end{array}$ & (Ozkumur et al., 2013) \\
\hline & & & $\begin{array}{l}\text { CTM differentially express } \\
\text { a subset of genes compared } \\
\text { to CTCs } \\
\text { Plakoglobin upregulated in } \\
\text { CTM and its knock-out } \\
\text { disintegrates CTM } \\
\text { Abundance of CTM denote } \\
\text { adverse outcomes in breast } \\
\text { cancer pateints }\end{array}$ & (Aceto et al., 2014) \\
\hline OncoBean Chip & $\begin{array}{l}\text { Bean shaped microposts } \\
\text { arranged radially and } \\
\text { functionalized with a } \\
\text { combination of Anti - } \\
\text { EpCAM, -EGFR, and - } \\
\text { CD133 }\end{array}$ & & $\begin{array}{l}\text { CTM detection in } \\
\text { preoperative specimens } \\
\text { predicts poor patient } \\
\text { outcome } \\
\text { Antiapoptotic gene } \\
\text { signature (increased IL6, } \\
\text { BCL2) } \\
\text { Increased invasiveness } \\
\text { (enrichment of IL17 } \\
\text { pathway) } \\
\text { Increased DNA repair } \\
\text { activity (elevated ERCC1 } \\
\text { expression) }\end{array}$ & (Murlidhar et al., 2017) \\
\hline
\end{tabular}




\begin{tabular}{|c|c|c|c|c|}
\hline \multirow[t]{2}{*}{ 3D Scaffold Chip } & $\begin{array}{l}\text { Anti-EpCAM functionalized } \\
\text { 3D macroporous PDMS } \\
\text { scaffold chip }\end{array}$ & $\begin{array}{l}\text { High efficiency capture by } \\
\text { combining two strategies: } \\
\text { chaotic cell migration } \\
\text { through spatially } \\
\text { distributed macroporous } \\
\text { structure, and enhanced } \\
\text { binding with antibodies } \\
\text { due to nanorough scaffold } \\
\text { surfaces } \\
\text { Flow rate: } 100 \mu \mathrm{l} / \mathrm{min}\end{array}$ & & (Cheng et al., 2016) \\
\hline & $\begin{array}{l}\text { Gelatin hydrogel coating of } \\
\text { chip }\end{array}$ & $\begin{array}{l}\text { Melting of gelatin hydrogel } \\
\text { at } 37^{\circ} \mathrm{C} \text { enables easy } \\
\text { retrieval of viable } \\
\text { CTCs/CTM }\end{array}$ & & (Cheng et al., 2017) \\
\hline \multirow[t]{2}{*}{ CMx Platform } & $\begin{array}{l}\text { Coating of channel with } \\
\text { anti-EpCAM conjugated } \\
\text { lipid bilayer }\end{array}$ & $\begin{array}{l}\text { Reduced non-specific } \\
\text { interactions between cells } \\
\text { and channel walls } \\
\text { Disrupting lipid-glass } \\
\text { surface interaction by } \\
\text { introducing air bubbles } \\
\text { enables easy CTC/CTM } \\
\text { release }\end{array}$ & $\begin{array}{l}\text { High number of CTM } \\
\text { (mean and median } 71.7 \text { and } \\
60 \text { respectively) isolated } \\
\text { from } 2 \mathrm{ml} \text { of blood in stage } \\
\text { IV CRC patients. } \\
\text { CTM count better able to } \\
\text { distinguish various CRC } \\
\text { compared to CTC count } \\
\text { CTM count distinguishes } \\
\text { CRC patients from healthy } \\
\text { subjects with } 67 \% \\
\text { sensitivity and } 89 \% \\
\text { specificity }\end{array}$ & (Chen et al., 2016) \\
\hline & & & $\begin{array}{l}29.5 \mathrm{CTM} \text { per } 2 \mathrm{~mL} \text { of } \\
\text { blood were detected in } 81 \% \\
\text { of the PDA patients } \\
\text { CTM number correlated } \\
\text { with disease stage }\end{array}$ & (Chang et al., 2016) \\
\hline
\end{tabular}




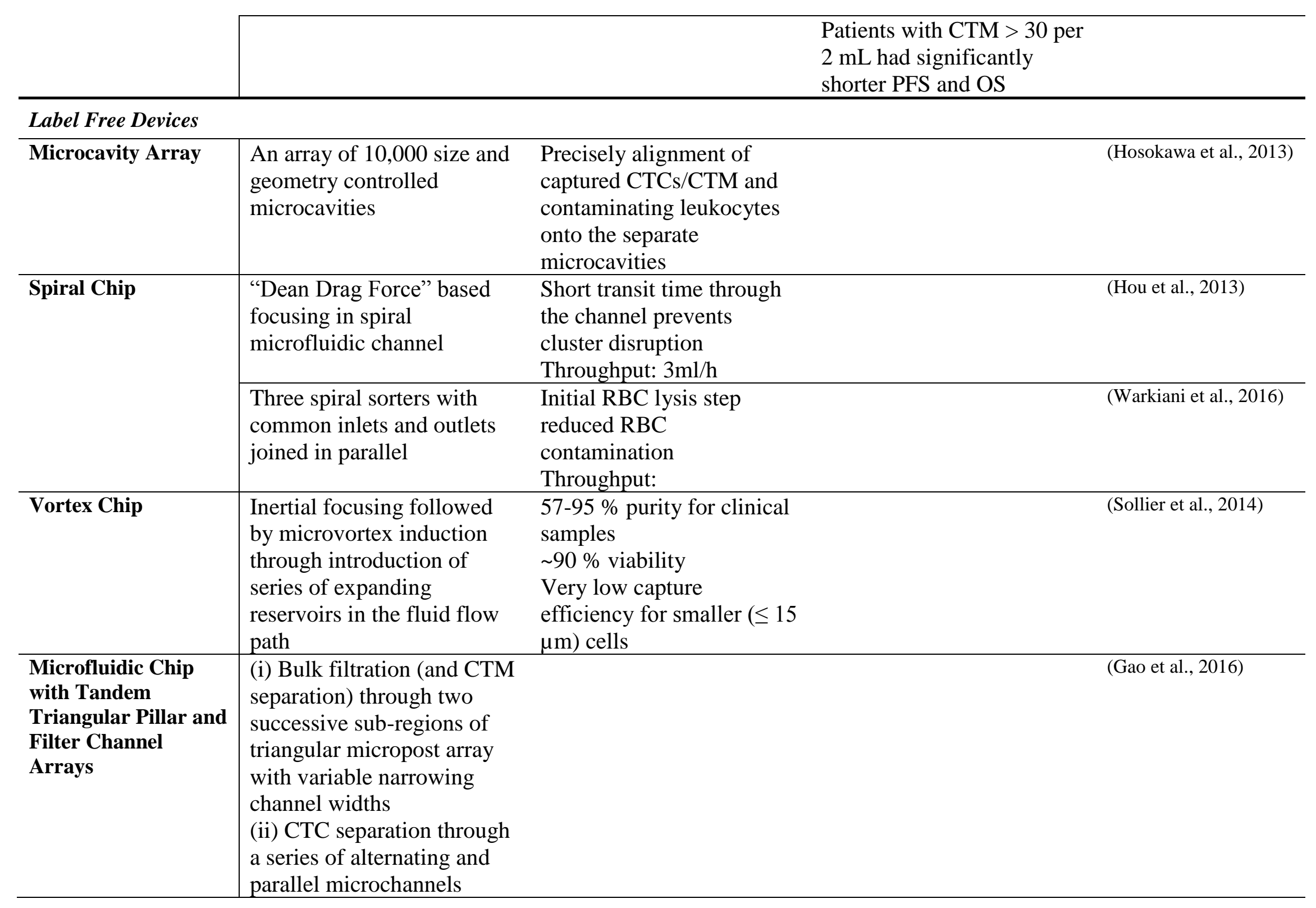




\begin{tabular}{|c|c|c|c|c|}
\hline & $\begin{array}{l}\text { interconnected through an } \\
\text { array of filtered channels }\end{array}$ & & & \\
\hline \multirow[t]{2}{*}{ Cluster Chip } & $\begin{array}{l}\text { Bifurcating traps in an array } \\
\text { of triangular pillars }\end{array}$ & $\begin{array}{l}99 \% \text { Capture efficiency for } \\
\geq 4 \text { cell CTM } \\
50 \%, 400 \% \text {, and } 1,000 \text {-fold } \\
\text { increased efficiency for } \\
\text { low, medium, and high } \\
\text { EpCAM expressing cells } \\
\text { compared to marker } \\
\text { dependent HB-Chip } \\
\text { High level of cluster } \\
\text { integrity, cell viability, and } \\
\text { release efficiency }\end{array}$ & $\begin{array}{l}\text { Heterogenous Ki67 } \\
\text { expression in CTM } \\
\text { Low but detectable levels } \\
\text { of CTC markers keratins, } \\
\text { MUC1, EpCAM and/or } \\
\text { CDH1 } \\
\text { CTM exist in a hybrid } \\
\text { epithelial-mesenchymal } \\
\text { state } \\
\text { No correlation between the } \\
\text { single CTC number and } \\
\text { number of CTM within a } \\
\text { sample } \\
2-19 \text { cell CTM detected in } \\
\text { up to } 40 \% \text { breast, } \\
\text { melanoma, and prostate } \\
\text { cancer patients ( 0.15- 0.5 } \\
\text { clusters/ml) }\end{array}$ & (Sarioglu et al., 2015) \\
\hline & & & $\begin{array}{l}\text { CTM traverse capillary } \\
\text { sized vessels by reversibly } \\
\text { reorganizing in to single- } \\
\text { file chain-like geometries }\end{array}$ & (Au et al., 2016) \\
\hline $\begin{array}{l}\text { Deterministic Lateral } \\
\text { Displacement Based } \\
\text { 2-stage Continuous } \\
\text { Flow Device }\end{array}$ & $\begin{array}{l}\text { Deterministic lateral } \\
\text { displacement through an } \\
\text { array of asymmetric hybrid } \\
\text { micropillars in tandem with } \\
\text { an array of cylindrical } \\
\text { micropillars }\end{array}$ & $\begin{array}{l}\text { Shear stress below that in } \\
\text { human blood } \\
\text { ( } 4.8 \text { vs 5-20Pa) } \\
\text { Capture purity suitable for } \\
\text { direct imaging and analysis } \\
\text { of CTM } \\
\text { No discreet release steps } \\
\text { required }\end{array}$ & & (Au et al., 2017) \\
\hline
\end{tabular}


Abbreviations: EGFR: Epithelial Growth Factor Receptor, BRCA: Breast Cancer, PCA: Prostate Cancer, PFS: Progression free survival, OS: Overall survival, CRC: Colorectal Cancer, PDA: Pancreatic Ductal Adenocarcinoma 


\section{Figures}

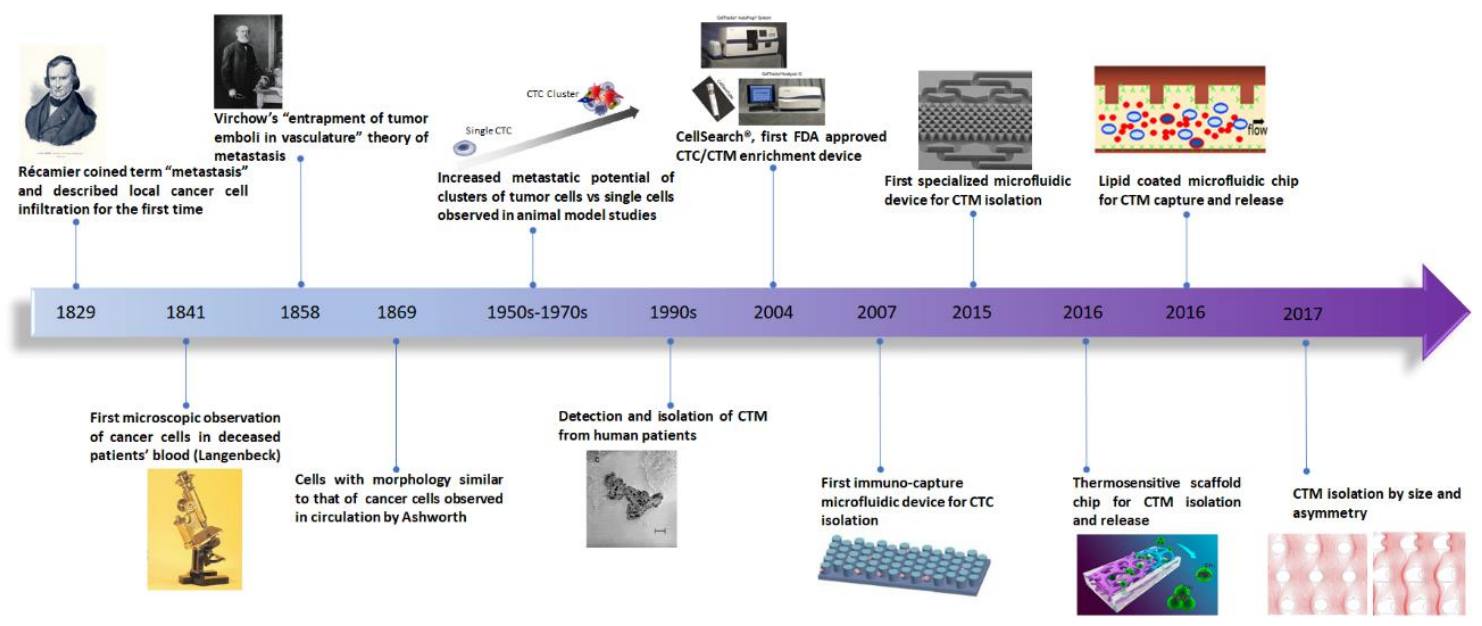

Figure 1: Milestones in CTC and CTM Research. Timeline representing key milestones in CTC discovery, clinical utility, and technological advances, particularly the developments in CTM research. 


\section{A: Collective Migration and Intravasation of CTM}

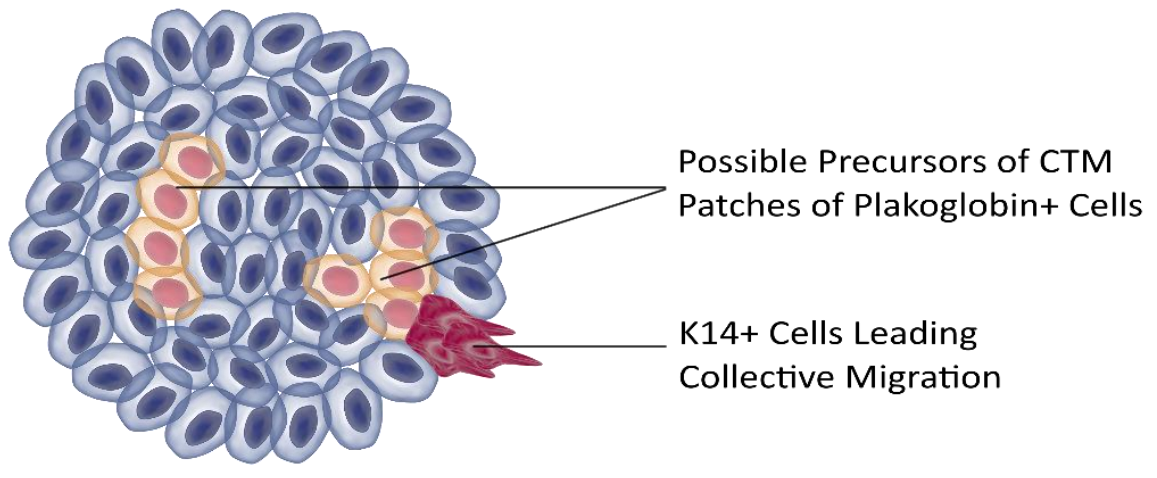

\section{Primary Tumor Mass}

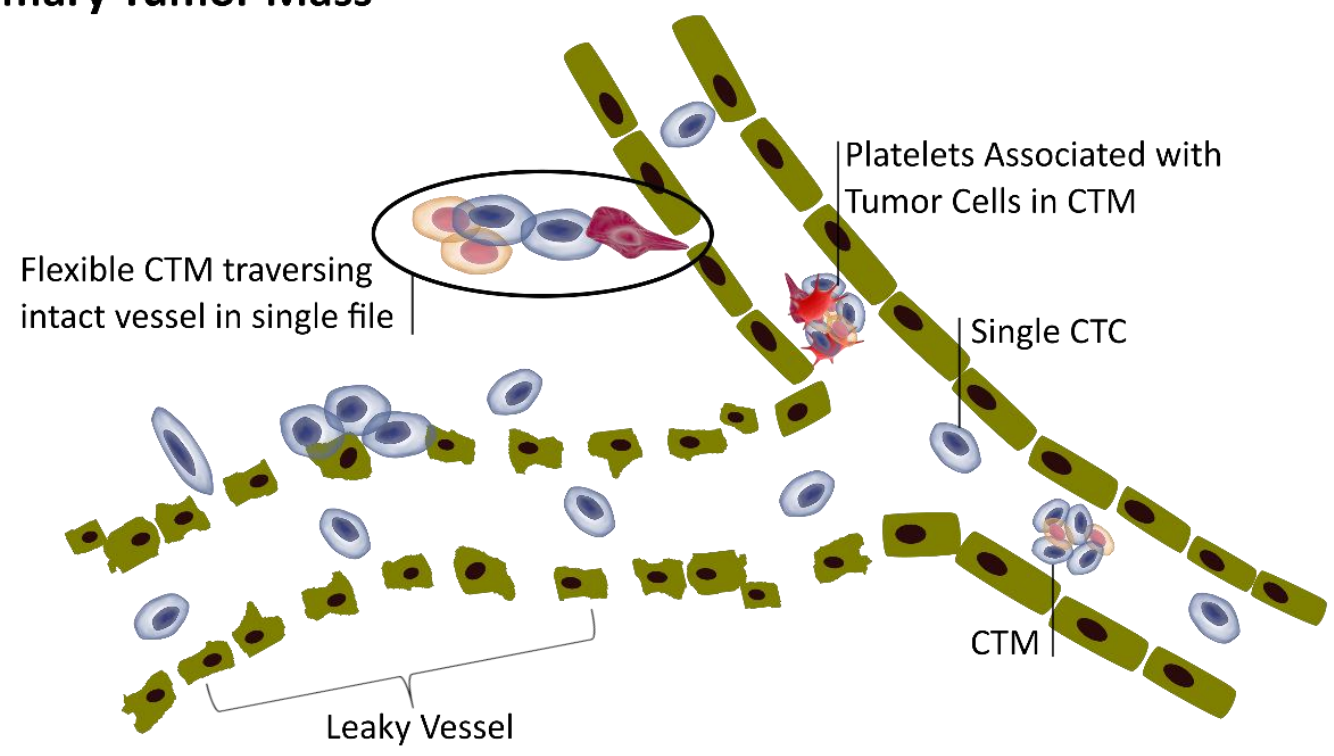

\section{B: Cellular Composition of CTM}

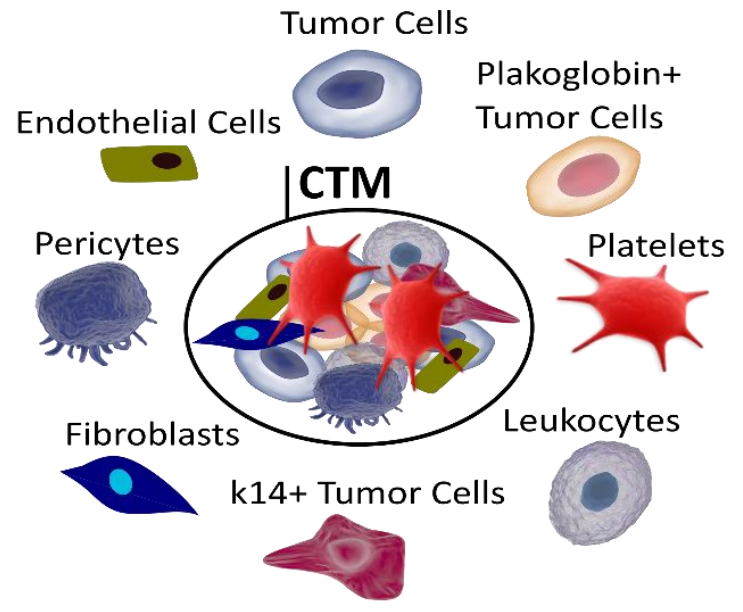


Figure 2: Model of CTM origin and mechanisms underpinning entry of CTM into the circulation. (A) Regions (or patches) of high plakoglobin expression in breast tumors are considered as possible precursors of CTM. $\mathrm{K}^{+} 4^{+}$cells close to the extracellular matrix (ECM) lead the collective migration. Notice the particular "protrusive" morphology of K14+ cells which helps them to invade through surrounding matrix (see section 2.5 for more details). Subsequently, CTM may enter the circulation either via "leaky vessels" or adopt reversible single-file chain-like geometries. (B) Cellular composition of heterotypic CTM may vary and the figure depicts only a general representation of all the cell types that have been reported to be associated with tumor cells in CTM 

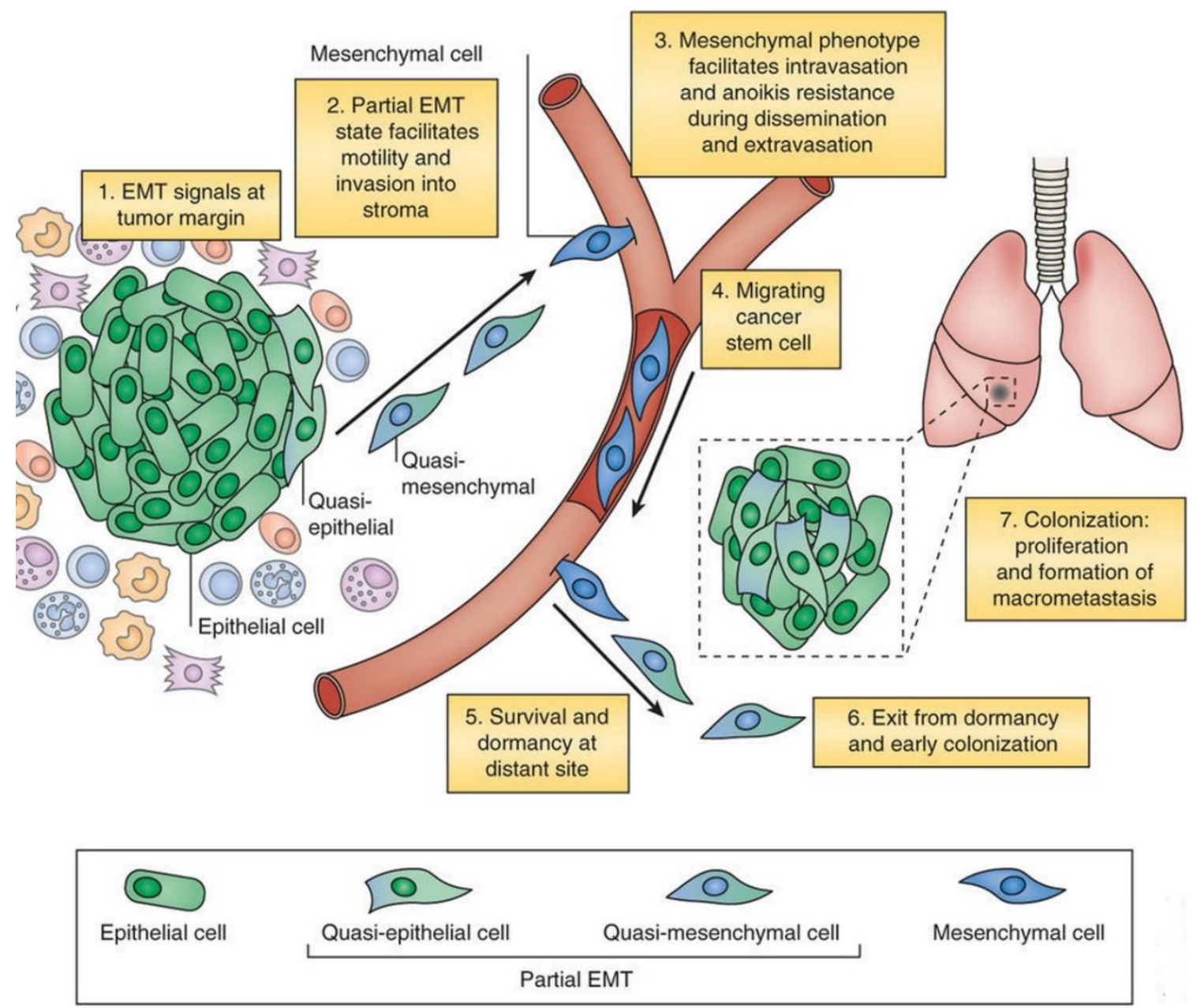

Figure 3: Epithelial-mesenchymal plasticity and its role in tumor cell invasion and metastasis.

During EMT cells close to the invasive edge of tumor lose their epithelial characteristics under the influence of various signaling pathways like; transforming growth factor $\beta$ (TGF- $\beta$ ), fibroblast growth factor (FGF), Wnt- $\beta$ Catenin signaling etc. These EMT-promoting signals induce specific transcription factors which in turn lead to the expression of EMT associated genes. Detachment of cells from primary mass reduces the influence of epithelial signals, while EMT signals from stromal cells continue to lead cells on the path of EMT. EMT facilitates cell motility and invasion of surrounding vessels as well as extravasation and invasion of tissues at the site of dissemination. At distant dissemination sites tumor cells may undergo reversal of EMT, namely mesenchymalepithelial transition (MET), and reacquire epithelial properties, especially rapid proliferative capabilities. Figure reproduced with permission from: (Tam and Weinberg, 2013) () Nature Publishing Group) 
A) Micropost array for CTC isolation

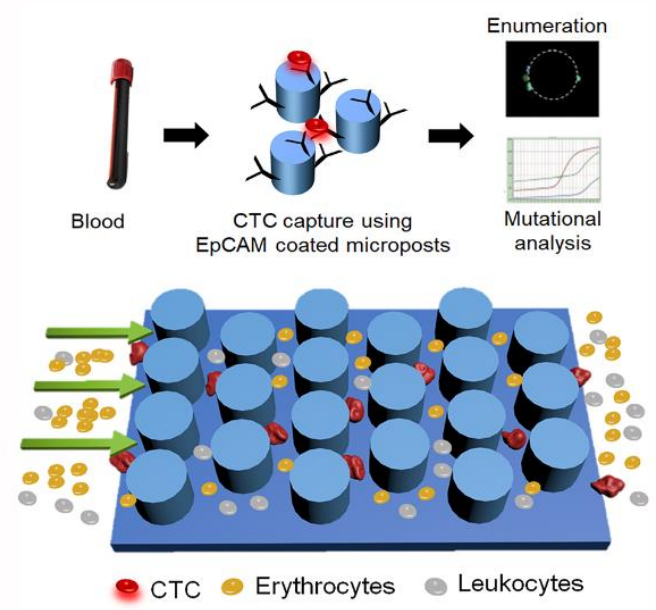

C) Integrated microchip for CTC separation

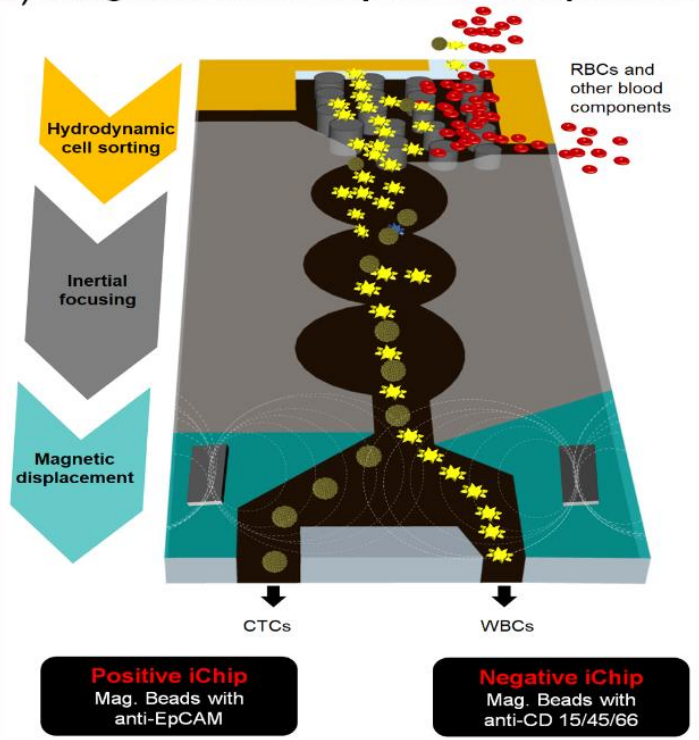

B) Convectional fluid mixing for improved capture

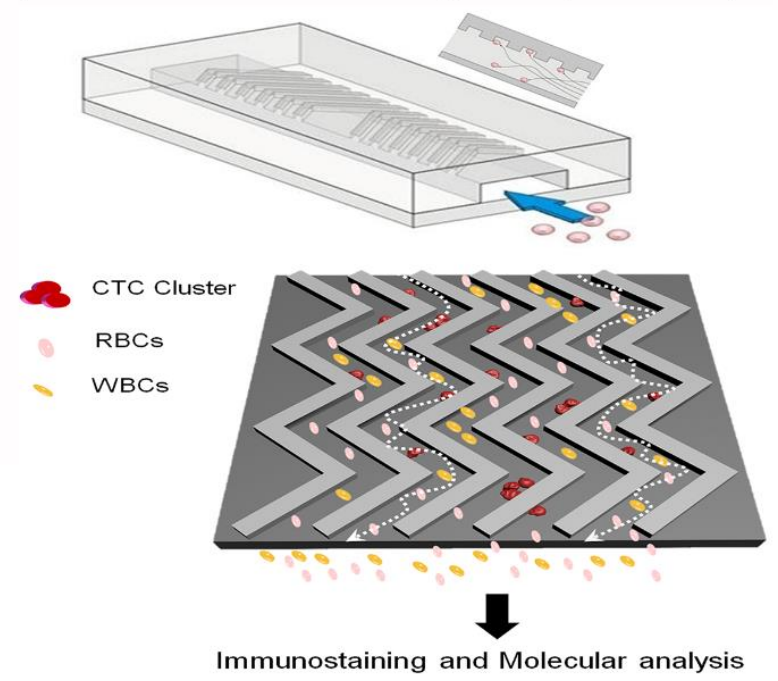

D) Scaffold microchip for СTC isolation and release

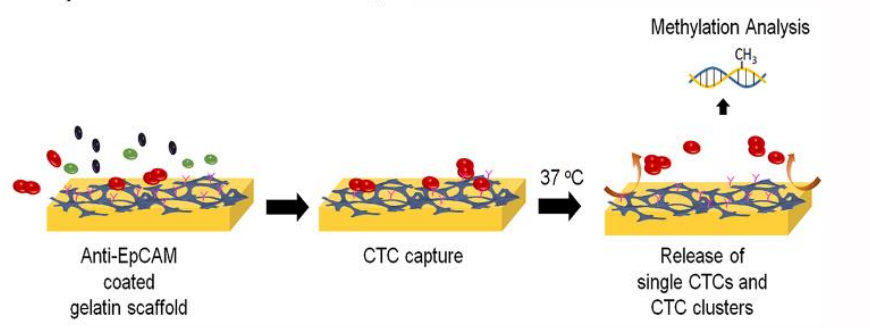

E) Lipid coated microchip for isolation and release

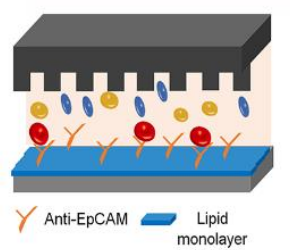

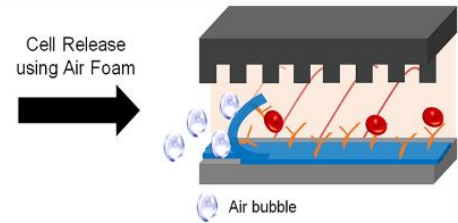

Figure 4: Marker-Dependent Methods for CTM Isolation. (A) CTC-Chip: (top) General workflow for sample processing on CTC-Chip (bottom) anti-EpCAM functionalized micropost array on CTC-Chip (B) Herringbone-Chip (HB-Chip): (top) grooved upper surface produces chaotic microvortices (bottom) chaotic mixing increases the frequency of CTCs/CTM with antibodies (C) Schematics and functioning of CTC-iChip (D) 3D Scaffold Chip: Thermosensitive gelatin hydrogel coated 3D scaffold chip for efficient capture and release of CTCs/CTM. (E) CMx Platform: Capture and release of CTCs/CTM on cell capture at maximum (CMx) platform.

Figures are adapted with permission from: (A) (Sequist et al., 2009), Copyright $($ International Association for the Study of Lung Cancer; (B) (Stott et al., 2010a), Copyright $($ PNAS; (C) Macmillan Publishers Ltd: [SciBX] (Baas, 2013) Copyright@ 2013; (D) (Cheng et al., 2017) Copyright $@$ 2017, American Chemical Society (E) (Chen et al., 2016) under the terms of the Creative Commons Attribution License. Copyright $(2016$ Chen et al. 
A) Microcavity array for CTC entrapment

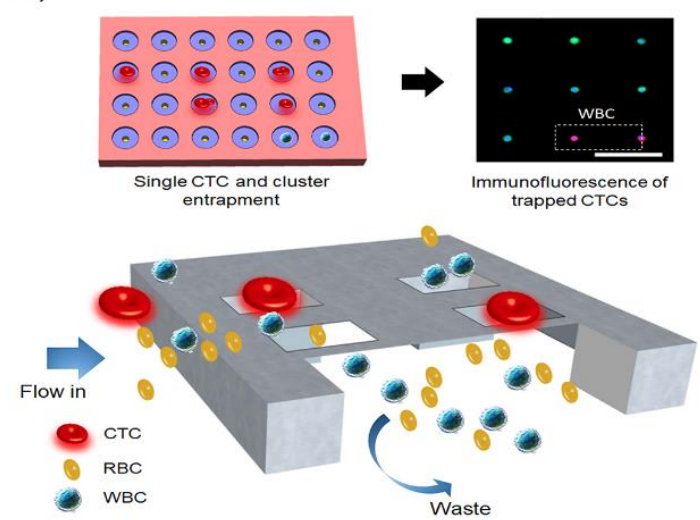

C) Micro-vortices and inertial focusing for CTC separation

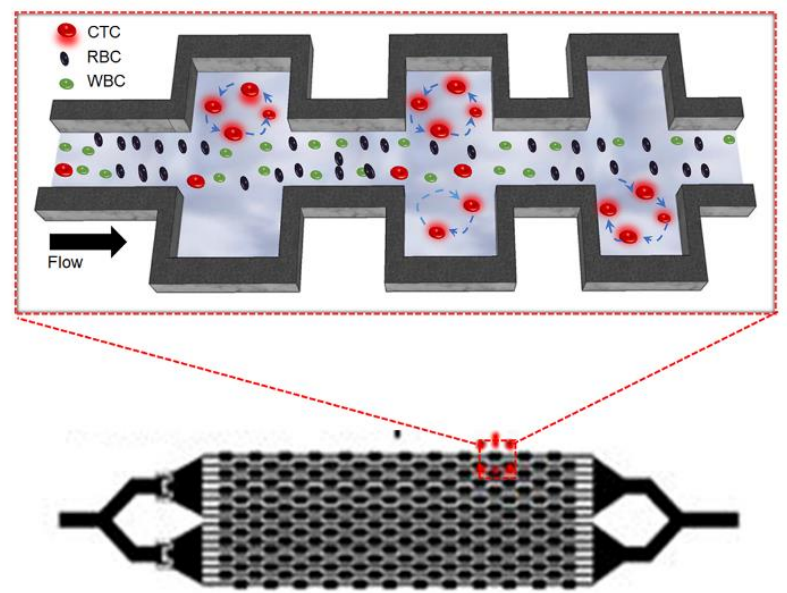

B) Selective focusing of CTC using spiral biochip

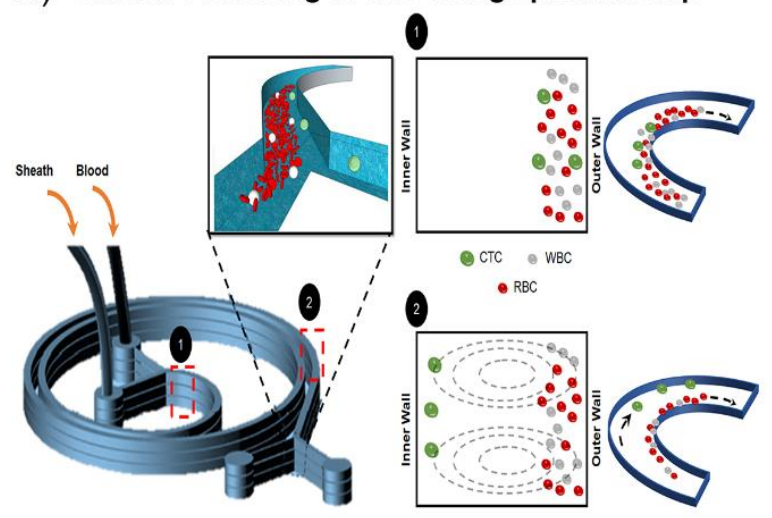

D) Bifurcating traps for selective CTC cluster isolation

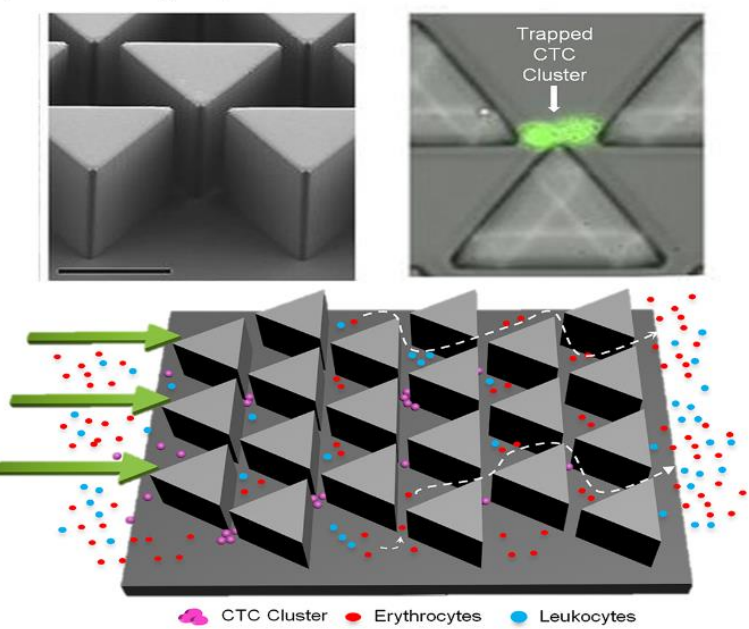

Figure 5: Label-Free Methods for CTM Isolation. (A) Microcavity Array: Schematic diagram of MCA system and its operation (B) Spiral Biochip: Cross sectional view of spiral bioship demonstrating the principal of "Dean Flow Fractionation" (DFF). (C) Vortex Chip: Introducing expanding reservoirs in fluid flow path forces CTCs/CTM to move in vortices and thus get separated from smaller blood cells (D) Cluster-Chip: (i) Design of Cluster-Chip. (top left) SEM image of individual cluster trap. (top right) CTM captured on cluster-chip (bottom) schematics of Cluster-Chip

Figures adapted redrawings with permission from: (A) (Hosokawa et al., 2013), Copyright@ 2013 Hosokawa, M. et al. (2013) PLoS One, 8(6), e67466 (B) Under Creative Commons CC0 license: (Hou et al., 2013); (C) (Sollier et al., 2014) Copyright@ Royal Society of Chemistry; (D) Macmillan Publishers Ltd: [Nature Methods], (Sarioglu et al., 2015) Copyright $\subset$ (2015) 